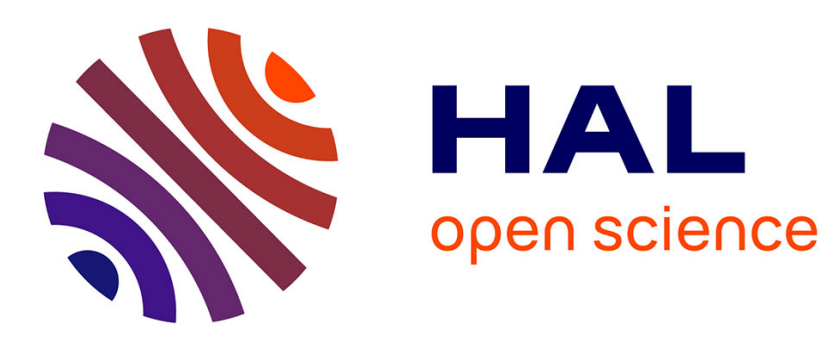

\title{
Influence of Tetrahedral Layer Charge on the Fixation of Cesium in Synthetic Smectite
}

\author{
Liva Dzene, Heloïse Verron, Alfred Delville, Laurent Michot, Jean-Louis \\ Robert, Emmanuel Tertre, Fabien Hubert, Eric Ferrage
}

\section{- To cite this version:}

Liva Dzene, Heloïse Verron, Alfred Delville, Laurent Michot, Jean-Louis Robert, et al.. Influence of Tetrahedral Layer Charge on the Fixation of Cesium in Synthetic Smectite. Journal of Physical Chemistry C, 2017, 121 (42), pp.23422 - 23435. 10.1021/acs.jpcc.7b06308 . hal-02325844

\section{HAL Id: hal-02325844 \\ https://hal.science/hal-02325844}

Submitted on 22 Oct 2019

HAL is a multi-disciplinary open access archive for the deposit and dissemination of scientific research documents, whether they are published or not. The documents may come from teaching and research institutions in France or abroad, or from public or private research centers.
L'archive ouverte pluridisciplinaire HAL, est destinée au dépôt et à la diffusion de documents scientifiques de niveau recherche, publiés ou non, émanant des établissements d'enseignement et de recherche français ou étrangers, des laboratoires publics ou privés. 


\section{Influence of Tetrahedral Layer Charge on the}

\section{Fixation of Cesium in Synthetic Smectite}

Liva Dzene $^{* a, t}$, , Heloïse Verron ${ }^{a, t \dagger}$, Alfred Delville $^{b}$, Laurent J. Michot ${ }^{c}$, Jean-Louis Robert ${ }^{d}$, Emmanuel Tertre $^{a}$, Fabien Hubert ${ }^{a}$ and Eric Ferrage $e^{a}$

${ }^{a}$ Université de Poitiers/CNRS, UMR 7285 IC2MP, Equipe HydrASA, 5 rue Albert Turpain, Bât. B8, TSA - 51106, 86073 Poitiers cedex 9, France

${ }^{\mathrm{b}}$ Interfaces, Confinement, Matériaux et Nanostructures - ICMN CNRS, UMR 7374, Université d'Orléans, 45071 Orléans Cedex 2, France

c Phenix CNRS-UPMC-Sorbonne Université UMR 8234, 4 place Jussieu case courrier 51, 75005 Paris, France

d IMPMC, Sorbonne Universités, UMR 7590, UPMC, CNRS, MNHN, IRD, 4 Place Jussieu, 75252 Paris Cedex 05, France

KEYWORDS Smectite hydration / molecular simulation / Cesium fixation / layer charge 


\section{ABSTRACT}

After radionuclides pollution of soils by nuclear power plant accidents, $\mathrm{Cs}^{+}$strongly interacts with swelling clay minerals, which in turn control the fixation or the migration of this pollutant in the natural media. Little is known, however, about the role played by the amount of layer charge and the two-dimensional confinement on $\mathrm{Cs}^{+}$fixation. In this study a series of

tetrahedrally charged smectites with structural formula ${ }^{\text {inter }}\left[M_{x}^{+}\right]^{\text {oct }}\left[\mathrm{Mg}_{6}\right]^{\text {tet }}\left[\mathrm{Si}_{8-x} \mathrm{Al}_{x}\right] \mathrm{O}_{20}(\mathrm{OH})_{4}$ with a layer charge $(x)$ varying from 0.8 to 2.0 and with $\mathrm{Na}^{+}$or $\mathrm{Cs}^{+}$as interlayer cation $\mathrm{M}^{+}$were used. While $\mathrm{Na}^{+}$remains fully exchangeable over the entire range of layer charges investigated, the fraction of exchangeable $\mathrm{Cs}^{+}$decreased gradually for samples with $x \geq 1.4 / \mathrm{O}_{20}(\mathrm{OH})_{4}$. Structure analysis of $\mathrm{Cs}^{+}$-samples in water-saturated or at $80 \%$ relative humidity conditions showed a gradual decrease of the layer-to-layer distance. The results were found to qualitatively agree with analysis of the thermodynamics of the clay/water interfaces derived from molecular simulations. Quantitative structure analysis by modeling of $00 \ell$ reflections on experimental Xray diffraction patterns suggested that exchangeable $\mathrm{Cs}^{+}$can be correlated with the amount of hydrated interlayers, whereas fixed $\mathrm{Cs}^{+}$in these conditions corresponds to the amount of collapsed layers. To describe the coexistence of both exchangeable and fixed $\mathrm{Cs}^{+}$, a toy-model accounting for the presence of heterogeneous charge distribution was used, in agreement with experimental data obtained on these samples. This model successfully interprets the overall reactivity of $\mathrm{Cs}^{+}$towards smectite over a large range of layer charge values and may contribute to an improved description of $\mathrm{Cs}^{+}$mobility in contaminated soil environments.

\section{INTRODUCTION}


Swelling clays such as smectites are lamellar silicates that are one of the main components of soils. The structure of these colloidal $(<2 \mu \mathrm{m})$ particles involves negatively charged 2:1 layers composed of an octahedral sheet sandwiched between two tetrahedral sheets. Isomorphic substitutions in variable amounts by less charged cations in tetrahedral (and/or octahedral) sheets induce a permanent negative charge. This layer charge is compensated by the presence of exchangeable cations that are responsible for high cation exchange capacity (CEC) values of these minerals. In addition, the hydration properties of interlayer cations are the main engine leading to the well-known stepwise expansion of the layer-to-layer distance (i.e. $\left.d_{001}\right)$ in the smectite structure. With increasing water content the mono-hydrated $\left(1 \mathrm{~W}, d_{001}=11.8-12.9 \AA\right)$, bi-hydrated $\left(2 \mathrm{~W}, d_{001}=14.5-15.8 \AA\right)$, and tri-hydrated $\left(3 \mathrm{~W}, d_{001}=18.0-19.5 \AA\right)$ states can be obtained in addition to the dehydrated state $\left(0 \mathrm{~W}, d_{001}=9.6-10.7 \AA\right){ }^{1,2}$

The two dimensional confinement of both water and cations in the interlayer space affects their dynamical properties, which plays a pivotal role on the transfer of pollutants in natural media. ${ }^{3}$ As an illustration, pollutants such as Cesium-137 released in soils after nuclear power plant accidents such as those that occurred in Chernobyl or Fukushima, ${ }^{4,5}$ strongly interact with clay minerals from soils. ${ }^{6-9}$ In the specific case of $\mathrm{Cs}^{+}$, previous studies revealed constrasted behaviors of this element upon its contact with smectite, as either reversible ion-exchange or irreversible $\mathrm{Cs}^{+}$fixation on the mineral were observed. In this framework, layer charge has been put forward as one of the key parameters controlling $\mathrm{Cs}^{+}$-clay interactions. ${ }^{1,8,10-13}$ However, most studies dealt with natural swelling clay samples with a restricted range of layer charge values. Consequently, up to now, the exact role played by layer charge and the associated twodimensional confinement on $\mathrm{Cs}^{+}$fixation in swelling clay minerals remains elusive. 
In the present study, synthetic swelling clay minerals (saponites) with layer charge varying from 0.8 to 2.0 per unit-cell (i.e., per $\mathrm{O}_{20}(\mathrm{OH})_{4}$ ) were used. ${ }^{14}$ These samples, whose crystal chemistry is much more controlled than that of natural clay minerals, were previously used to refine the role played by layer charge and cation nature on the organization and dynamics of interlayer species. ${ }^{15-22}$ These studies evidenced that layer charge increase significantly enhances the positional order of water molecules and interlayer cations, which, in turn, likely impacts the fixation or the exchangeability of interlayer cations such as $\mathrm{Cs}^{+}$. A first part of this paper focuses on extraction measurements of interlayer $\mathrm{Cs}^{+}$and $\mathrm{Na}^{+}$as a function of layer charge. Evolution of cation extraction as a function of layer charge or type of interlayer cation is then balanced against quantitative analyses of structural hydration properties derived by X-ray techniques, and qualitative information on the thermodynamics of clay/water interfaces obtained using GrandCanonical Monte-Carlo (GCMC) and molecular dynamics (MD) simulations. Finally, information on interlayer hydration properties is used to propose a structure model of $\mathrm{Cs}^{+}$ fixation based on a heterogeneous layer charge distribution.

\section{EXPERIMENTAL METHODS}

Material. The synthetic saponite samples used in the present study have a common structural formula ${ }^{\text {inter }}\left[M_{x}^{+}\right]^{\text {oct }}\left[\mathrm{Mg}_{6}\right]^{\text {tet }}\left[\mathrm{Si}_{8-x} \mathrm{Al}_{x}\right] \mathrm{O}_{20}(\mathrm{OH})_{4}$ with a layer charge $(x)$ varying from 0.8 to 2.0 and with a monovalent interlayer cation $M^{+}$as $\mathrm{Na}^{+}$or $\mathrm{Cs}^{+}$. The synthesis protocol and the detailed characterization of these materials is given elsewhere. ${ }^{14}$ Samples are hereafter referred to as $M$ Sap- $x$. 
Sample saturation and cation extraction measurements. Series of $\mathrm{Na}^{+}-$and $\mathrm{Cs}^{+}$-saturated saponites (i.e., Na-Sap- $x$ and Cs-Sap- $x$, respectively) were obtained by saturation of synthesis products with $1 \mathrm{~mol} \cdot \mathrm{L}^{-1} \mathrm{NaCl}$ or $\mathrm{CsCl}$ solutions, respectively, following the conventional saturation protocol. ${ }^{23}$ For all Na-Sap- $x$ and Cs-Sap- $x$ samples a fraction of solid was used to measure cation exchange capacity by exchanging the original interlayer cation by $\mathrm{NH}_{4}{ }^{+}$using $1 \mathrm{~mol} \cdot \mathrm{L}^{-1} \mathrm{CH}_{3} \mathrm{COONH}_{4}$ solution. About $25 \cdot 10^{-3} \mathrm{~g}$ of dried sample were put in contact with $7 \cdot 10^{-}$ ${ }^{3} \mathrm{~L}$ of acetate solution for three days on a mechanical shaker. The samples were then centrifuged and the supernatants were collected for further analyses. The same procedure was repeated for another three days renewing the acetate solution. The aqueous $\mathrm{Na}^{+}$and $\mathrm{Cs}^{+}$cation concentrations in $\mathrm{NH}_{4}{ }^{+}$-exchanger solutions were determined by atomic absorption spectroscopy (AAS, Varian AA240FS). All CEC and extraction measurement values are given in meq per 100g of air-dried clay. The detection limit of AAS was $0.5 \cdot 10^{-3} \mathrm{~g} \cdot \mathrm{L}^{-1}$ for both $\mathrm{Na}$ and Cs. Samples were diluted in $2 \% \mathrm{HNO}_{3}$ to measure aqueous concentrations between 0.5 and $5 \cdot 10^{-3} \mathrm{~g} \cdot \mathrm{L}^{-1}$ corresponding to linear ranges of the calibration curves. To account for possible interferences, $2 \mathrm{~g} \cdot \mathrm{L}^{-1} \mathrm{KNO}_{3}$ was added to the samples and standards. Total uncertainties in the measured concentrations of all cations were estimated to be $\pm 2 \%$.

Wide angle $X$-ray scattering experiments in water-saturated conditions. Wide angle X-ray scattering (WAXS) experiments were performed for retrieving layer-to-layer distances (i.e., $d_{001}$ values) for Na-Sap- $x$ and Cs-Sap- $x$ samples in water-saturated conditions. Aqueous dispersions at an initial solid/solution ratio of $50 \mathrm{~g} \cdot \mathrm{L}^{-1}$ were filled into $0.5 \mathrm{~mm}$ diameter glass capillaries by mild centrifugation and stored vertically after sealing with wax. A clear settling tendency could be observed in the capillaries for most samples. WAXS measurements were performed on a home-made setup at Laboratoire de Physique des Solides (Orsay, France). The beam was 
generated by rotating copper anode at $40 \mathrm{kV}$ and $40 \mathrm{~mA}\left(\lambda_{\mathrm{CuK \alpha}}=1.5418 \AA\right)$. The $2 \mathrm{D}$ scattering patterns were collected on a Dectris ${ }^{\circledR}$ Pilatus $200 \mathrm{~K}$ photon counting detector with $172 \mu \mathrm{m}$ pixel size at a distance of $64 \mathrm{~mm}$ from the sample. The accessible range of scattering vector modulus $\mathrm{q}$ was $\sim 0.2-3.6 \AA^{-1}$ (i.e., from $\sim 1.7$ to $\sim 30.2 \AA$ ) with $\mathrm{q}=4 \pi(\sin \theta) \cdot \lambda^{-1}$, where $2 \theta$ is the scattering angle. The obtained experimental 2D scattering patterns were first corrected from the scattering signal of empty capillary and water. Scattering patterns were radially averaged to obtain the scattering curves $I(q)$ and peak positions were calibrated using as a standard the pattern obtained for $\mathrm{Ca}^{2+}$-saturated vermiculite whose layer-to-layer distance in water-saturated conditions is equal to $15 \AA .{ }^{11}$ Finally, the RGB color scheme was adopted by normalizing the image with respect to the most intensive pixel with red being 1 and blue 0 .

Small angle X-ray scattering experiments on suspensions. Small-angle X-ray scattering (SAXS) experiments were carried out at the Swing SAXS beamline of the SOLEIL synchrotron radiation facility (Saint-Aubin, France). Measurements were performed at a fixed energy of 12.0 $\mathrm{keV}$ and a sample-to-detector distance of $6.56 \mathrm{~m}$. The 2D scattering patterns were recorded on an AVIEX 170170 CCD camera formed by four detectors placed in a vacuum detection tunnel. Same corrections and normalization as for WAXS measurements were applied on the obtained SAXS patterns.

X-ray diffraction measurements. Additional X-ray diffraction (XRD) experiments were performed on oriented preparations of Cs-Sap- $x$ series to gain more information regarding structural heterogeneity. These oriented preparations were obtained by dropping an aliquot of the Cs-Sap- $x$ clay dispersion (never dried after the saturation process in order to avoid any irreversible collapse of the structure) onto a glass slide and equilibrated at $\sim 75 \%$ relative 
humidity (RH) using saturated $\mathrm{NaCl}$ solution at $20^{\circ} \mathrm{C}$. The $\mathrm{XRD}$ patterns were recorded using a Panalytical X'Pert Pro MPD diffractometer equipped with an X'Celerator detector operating with an angular aperture of $2.127^{\circ}$ at $80 \% \mathrm{RH}$. The relative humidity conditions were fixed using a VTI RH-100 humidity generator device coupled with an Anton Paar THC chamber. Samples were allowed to equilibrate for $20 \mathrm{~min}$ before recording. The scanning parameters were a step size of $0.033^{\circ} 2 \theta$ and a counting time of $12 \mathrm{~s}$ per step over the $2-50^{\circ} 2 \theta \mathrm{CuK}_{\alpha}$ angular range. The divergence slit, the anti-scatter slit and the two Soller slits were set at $0.125^{\circ}, 0.25^{\circ}, 2.3^{\circ}$ and $2.3^{\circ}$, respectively.

$X$-ray diffraction profile modeling of 00ใ reflections. Three samples, corresponding to Cs-Sap0.8, Cs-Sap-1.2 and Cs-Sap-2.0, were selected for quantitative analysis of structural heterogeneity. The algorithms developed by Sakharov and Drits were used to fit the experimental XRD patterns by using a trial-and-error approach. ${ }^{24-26}$ Instrumental and experimental factors, such as horizontal and vertical beam divergences, goniometer radius, length and thickness of the oriented slides were measured and introduced without further adjustment. The mass absorption coefficient $\left(\sigma^{*}\right)$ was set to $45 \mathrm{~cm}^{2} \cdot \mathrm{g}^{-1}$, as recommended. ${ }^{27}$ Additional variable parameters include the layer-to-layer distance and the coherent scattering domain size (CSDS) along the $\mathrm{c}^{*}$ axis that was characterized by a lognormal distribution around a variable mean value $(\mathrm{N})$ and a maximum CSDS value of 80 layers. ${ }^{28}$ The layer-to-layer distance was allowed to deviate from its mean value by introducing a variance parameter $\sigma_{\mathrm{z}}$, that was $0.05,0.14$ and $0.10 \AA$ for samples CsSap-0.8, Cs-Sap-1.2 and Cs-Sap-2.0, respectively, to account for this "disorder of the second type". ${ }^{29,30}$ The $\mathrm{z}$-coordinates for all atoms within the 2:1 layer framework were set as proposed by Moore and Reynolds. ${ }^{27}$ The interlayer configuration used for bihydrated layers (2W, $d_{001} \sim 14.5 \AA$ ) was initially proposed by Ferrage et al. ${ }^{29}$, with one plane of $\mathrm{H}_{2} \mathrm{O}$ molecules on each 
side and at $1.20 \AA$ distance of the interlayer midplane hosting cations. For monohydrated layers ( $1 \mathrm{~W}, d_{001} \sim 12.6 \AA$ ) cations and $\mathrm{H}_{2} \mathrm{O}$ molecules were both located in the interlayer midplane. A similar configuration was used for dehydrated layers $\left(0 \mathrm{~W}, d_{001} \sim 10.7 \AA\right)$ without interlayer water molecules. The water content was set to 3 and $9 \mathrm{H}_{2} \mathrm{O}$ molecules per $\mathrm{O}_{20}(\mathrm{OH})_{4}$ for the $1 \mathrm{~W}$ and 2W layers, respectively. ${ }^{2}$ The Debye-Waller factor of $\mathrm{H}_{2} \mathrm{O}$ molecules was set at $30 \AA^{2}$ for $1 \mathrm{~W}$ layers and $10 \AA^{2}$ for $2 \mathrm{~W}$ layers to optimize the electronic density profile of the interlayer species, as proposed by Dazas et al. ${ }^{19,31,32}$ The fitting procedure is detailed elsewhere. ${ }^{29,33}$ Briefly, one periodic sequence of layers $(0 \mathrm{~W}, 1 \mathrm{~W}$, or $2 \mathrm{~W}$ only) was used first to reproduce as much as possible of the experimental XRD pattern. If necessary, a second contribution containing two or three layer types was added to the calculated profile to account for the misfit between calculated and experimental patterns. Note that considering two mixed-layer structures (MLSs) does not imply the actual presence of different populations of particles in the sample but rather indicates that layer nature and hydration heterogeneities are not randomly distributed within crystallites. For each XRD pattern, structural parameters, such as the composition of the different MLSs (i.e., proportions of the different layer types), their stacking mode (Reichweite parameter R, junction probabilities), and an estimate of their relative proportions, were adjusted to fit the experimental XRD pattern. The quality of fit is characterized by the Rp parameter, ${ }^{34}$ which is mainly influenced by the fit quality of the intense diffraction maxima.

Grand-Canonical Monte Carlo simulations. At large layer-to-layer distances (i.e. $>40 \AA$ ) the diffuse layer theory ${ }^{35-38}$ perfectly reproduces the swelling behavior of the clay/water interface by neglecting the molecular structure of the solvent in the framework of the Primitive Model. ${ }^{39}$ By contrast, at small layer-to-layer distances (i.e., $<40 \AA$ ), a molecular model of the clay/water interface is required to understand its thermodynamics. ${ }^{40,41}$ For that purpose, the classical Clay 
Force Field ${ }^{42}$ with modifications suggested by Ferrage et al. ${ }^{16}$ in addition to the SPC model of flexible water ${ }^{43}$ were used to describe the stability of the clay/water interface as a function of the chemical nature of the neutralizing counterions. Monte Carlo simulations were first performed in the Grand Canonical Ensemble ${ }^{44,45}$ at $298 \mathrm{~K}$ in order to determine the number of confined water molecules in equilibrium with a reservoir of bulk water $\left(\mathrm{p} / \mathrm{p}^{\circ}=1\right)$. The simulations were performed with four different clay/water interfaces, describing respectively two contrasted charge densities of the clay layers $\left(0.8\right.$ and 1.8 per $\left.\mathrm{O}_{20}(\mathrm{OH})_{4}\right)$ each neutralized either by $\mathrm{Na}^{+}$or $\mathrm{Cs}^{+}$cations. Each clay layer encompasses 6 and 4 unit cells respectively in the $a$ and $b$ directions, leading to a section of $31.92 \times 36.84 \AA^{2}$. The layer-to-layer distances were varied uniformly between 10 and $20 \AA$ with steps of $0.25 \AA$ for the smallest charge density and $0.5 \AA$ for the highest. Either two or three clay layers were considered, depending on the layer-to-layer distance, in order to maintain the whole simulation cell as cubic as possible. The Coulomb potential was evaluated by using classical Ewald summation ${ }^{46,47}$ with 3D periodic boundary conditions.

Molecular Dynamics simulations. After thermalisation of the GCMC simulations, one equilibrium configuration of the confined ions and water molecules was selected for each layer charge, interlayer cation and layer-to-layer distance to initialize MD simulations. The MD simulations were performed in the Canonical Ensemble by using a Verlet algorithm ${ }^{45}$ with a time step of $1 \mathrm{fs}$. The temperature $(\mathrm{T}=298 \mathrm{~K})$ was stabilized by using a Berendsen thermostat. ${ }^{48}$ The global interfacial free energy $\Delta \mathrm{F}^{\text {tot. }}$ as well as its electrostatic $\left(\Delta \mathrm{F}^{\text {elec. }}\right)$ and short-ranged Van der Waals $\left(\Delta \mathrm{F}^{\mathrm{VdW}}\right)$ contributions were obtained by integrating the longitudinal pressure $P_{z}$ as a function of the layer-to-layer distance. The virial theorem ${ }^{49}$ was frequently used to evaluate the longitudinal component of the pressure tensor. ${ }^{50-53}$ Recently, ${ }^{54}$ a more accurate procedure was 
used by applying a perturbation method. ${ }^{55,56}$ For that purpose, a fictitious variation of the layerto-layer distance $\Delta z$ is performed without deformation of the flexible clay layers and water molecules. Accordingly, the longitudinal pressure $P_{z}$ is obtained from the sum of its ideal and excess terms with

$$
P_{Z}^{\text {ideal }}=\frac{k T\left(N_{\text {water }}+N_{\text {cations }}\right)}{S \cdot l_{\text {tot }}}
$$

where $S$ and $l_{\text {tot }}$ stand for the section and length (along z direction) of the simulation box, respectively. $N_{\text {water }}$ and $N_{\text {cations }}$ corresponds to the amount of water molecules and interlayer cations, respectively. The excess term of the longitudinal pressure is calculated from the excess contribution of the canonical partition function $Q^{\text {excess }}$. By using a second order approximation, ${ }^{55,56}$ this terms reduces to an evaluation of the difference in potential energy $\Delta U$ as:

$$
P_{Z}^{\text {excess }}=\frac{k T \Delta \ln Q^{\text {excess }}(\Delta z)}{S \Delta z}=\frac{k T \ln \int_{0}^{1} \int_{0}^{1} \ldots \int_{0}^{1} \exp \left[-\frac{\Delta U(\Delta z)}{k T}\right] d s_{1} d s_{2} \ldots d s_{3 N}}{S \Delta z}=-\frac{\left\{\langle\Delta U\rangle-\frac{1}{2 k T}\left[\left\langle(\Delta U)^{2}\right\rangle-\langle\Delta U\rangle^{2}\right]\right\}}{S \Delta z}
$$

The fictitious variations $\left(\Delta \mathrm{z}= \pm 10^{-4} \AA\right)$ are randomly selected to validate the above-mentioned approximation while maintaining the numerical accuracy for the evaluation of difference in potential energy $\Delta U$.

\section{RESULTS AND DISCUSSION}


Cation extraction as function of layer charge. Figure 1 reports the measured amount of interlayer $\mathrm{Na}^{+}$or $\mathrm{Cs}^{+}$(i.e., $q_{\mathrm{Na}^{+}}$and $q_{\mathrm{Cs}^{+}}$) desorbed from the interlayer after exchange with $\mathrm{NH}_{4}{ }^{+}$. The obtained values are compared to theoretical CEC values calculated from structural formulae. Note that theoretical CEC values slightly differ for a given layer charge between NaSap- $x$ and Cs-Sap- $x$ series due to the contrasted molar mass of the two interlayer cations and contrasted water amounts (ranging from 6-10 and 0-4 $\mathrm{H}_{2} \mathrm{O}$ molecules per $\mathrm{O}_{20}(\mathrm{OH})_{4}$ for Na-Sap- $x$ and Cs-Sap- $x$ samples, respectively ${ }^{15}$ ). For Na-Sap- $x$ sample series the extracted $q_{\mathrm{Na}^{+}}$amounts using $1 \mathrm{~mol} \cdot \mathrm{L}^{-1} \mathrm{CH}_{3} \mathrm{COONH}_{4}$ as exchanger solution, correctly match the theoretical $\mathrm{CEC}$ values (Figure 1a). The obtained results are in addition fully consistent with previously reported extraction measurements with hexa-amine cobalt (II) ion $\left[\mathrm{Co}\left(\mathrm{NH}_{3}\right)_{6}\right]^{3+}$ as exchanger agent. ${ }^{14}$ Note however that for the two samples with the highest layer charges, i.e., Na-Sap-1.8 and NaSap-2.0, the extracted $q_{\mathrm{Na}^{+}}$amounts are lower compared to the theoretical ones. As discussed by Pelletier et al. ${ }^{57}$ on the basis of ${ }^{27} \mathrm{Al}$ MAS NMR measurements, this difference is related to the presence of $\mathrm{Al}^{3+}$ localization not only in tetrahedral sheet, but also in octahedral sheet. For these two high-charge samples, the octahedral sheet thus bears some positive charge that compensates a small part of the negative charge located in the tetrahedral sheet, resulting in turn in slightly lower extractable $q_{\mathrm{Na}^{+}}$values (Figure 1a). Despite this marginal difference, the extraction measurement for Na-Sap- $x$ series is consistent with theoretical CEC values of the samples. Desorbed amounts of $\mathrm{Cs}^{+}\left(q_{\mathrm{Cs}^{+}}\right)$as a function of layer charge for Cs-Sap- $x$ sample series clearly display a trend significantly different from that obtained for Na-Sap- $x$ samples (Figure 1b). For low-charge Cs-Sap-0.8 and Cs-Sap-1.0 samples, extracted $q_{C_{s}^{+}}$amounts are consistent with expected contents from the theoretical CEC value. For other Cs-Sap- $x$ samples, the noticeable 
decrease of extracted $q_{C s^{+}}$contents with increasing layer charge clearly evidences a gradual rise of the amount of fixed $\mathrm{Cs}^{+}$in the interlayer space of smectite.

The $\mathrm{Cs}^{+}$fixation in the interlayer space of high-charge swelling clay minerals and $\mathrm{Cs}^{+}$exchange in low-charge swelling clay minerals have already been reported in the case of natural samples. It was for instance shown that $\mathrm{Cs}^{+}$adsorption on vermiculite whose layer charge is rather high (1.2 to 1.8 per $\mathrm{O}_{20}(\mathrm{OH})_{4}$ according to clay mineral nomenclature) was poorly reversible, ${ }^{8,11,12,58}$ The mechanism of irreversible $\mathrm{Cs}^{+}$fixation in this mineral was assigned to the dehydration and subsequent collapse of the interlayer upon $\mathrm{Cs}^{+}$adsorption in water-saturated conditions, ${ }^{58}$ leading to a structural trapping of the cation. Such an interpretation was further supported by Dzene et al. ${ }^{59}$ who evidenced that when structure collapse was inhibited due to the presence of interlayer hydroxy-Al cations in vermiculite interlayers, reversible exchange of $\mathrm{Cs}^{+}$could occur. In contrast, in the case of montmorillonite whose layer charge is rather low (0.6 to 1.2 per $\mathrm{O}_{20}(\mathrm{OH})_{4}$ according to clay mineral nomenclature) reversible $\mathrm{Cs}^{+}$exchange has been reported, ${ }^{10}$ which concurs with the fact that this mineral is known to exhibit hydrated interlayer in watersaturated conditions. ${ }^{60}$ Consequently, the tendency exhibited in Figure $1 \mathrm{~b}$ can be tentatively assigned to the progressive structural trapping of interlayer $\mathrm{Cs}^{+}$with increasing layer charge (Figure 1b) due to a gradual collapse of structure upon exchange.

Structural hydration in water-saturated conditions. In view of the possible link between reversibility of cation adsorption and swelling or collapsed behavior of the layers in watersaturated conditions, further analysis of the system was carried out using WAXS experiments. Experimental 2D WAXS patterns for Na-Sap- $x$ and Cs-Sap- $x$ sample series are given in Figure 2, whereas their respective layer-to-layer distances ( $d_{001}$ values) are reported in Table 1 . As far as 
Na-Sap-0.8 sample is concerned, no diffraction feature is observed in the WAXS angular window (Figure 2). Small Angle X-ray scattering experiments reveal however a correlation peak corresponding to a distance around $34 \mathrm{~nm}$, which is consistent with the osmotic swelling of low charge $\mathrm{Na}^{+}$-saturated saponite. For all other samples, experimental 2D WAXS indicate a flocculated behavior when immersed in water leading to the presence of well-defined diffraction rings. For Na-Sap- $x$ series, the obtained $d_{001}$ values are close to $15 \AA$ (Table 1 ) corresponding to a bihydrated state of the interlayer space, in agreement with results reported by Suquet. ${ }^{61}$ Note the slight decrease in layer-to-layer distances for the samples with the two highest layer charges, (i.e., Na-Sap-1.8 and Na-Sap-2.0, Table 1). Such a decrease is fully consistent with structural analyses performed on the water vapor adsorption features of these samples ${ }^{15,19}$ that revealed a decrease of interlayer volume upon an increase in layer charge resulting from stronger layercation electrostatic attraction. Still, whatever the layer charge, in water-saturated conditions the structure remains fully hydrated, which prevents from structural collapse and subsequent trapping of $\mathrm{Na}^{+}$cations in the interlayer, in agreement with extractability measurements (Figure 1a). The situation significantly differs in the case of Cs-Sap- $x$ samples that display smaller layerto-layer distances through the whole range of layer charges (Figure 2, Table 1). The $d_{001}$ value at $\sim 12.5 \AA$ for low charge Cs-Sap- $x$ samples $\left(x \leq 1.2\right.$ per $\mathrm{O}_{20}(\mathrm{OH})_{4}$, Table 1) corresponds to the socalled monohydrated state, similar to the hydration state commonly reported for $\mathrm{Cs}^{+}$-saturated montmorillonite. ${ }^{60}$ Swelling of low charge Cs-Sap- $x$ samples is consistent with desorbed $\mathrm{Cs}^{+}$ amounts that correspond to their theoretical CEC (Figure 1b). For higher layer charges $(x>1.2$ per $\mathrm{O}_{20}(0 \mathrm{H})_{4}$, Table 1$)$, the obtained $d_{001}$ values noticeably decrease with increasing layer charge, thus pleading for a gradual structural trapping of interlayer $\mathrm{Cs}^{+}$(Figure 1b, Table 1) also evidenced by diminishing amounts of desorbed $\mathrm{Cs}^{+}$. Such an interpretation is consistent with the 
layer-to-layer distance for the end-member Cs-Sap-2.0 reported at $\sim 11.6 \AA$ (Table 1) in fair agreement with the dehydrated/collapsed structure of vermiculite with a $d_{001}$ value at $\sim 11 \AA^{58}$ where interlayer $\mathrm{Cs}^{+}$is fixed.

Molecular modeling of clay/water interfaces. Molecular simulations were undertaken in order to obtain additional information regarding the influence of interlayer cation and layer charge on the thermodynamics of clay/water interfaces and thus on the swelling or collapse of the layers in water-saturated conditions. GCMC and MD simulations were performed on four samples, i.e., Na-Sap-0.8, Na-Sap-1.8, Cs-Sap-0.8, and Cs-Sap-1.8. Firstly, a higher water content is noticed for Na-Sap-0.8 compared to Cs-Sap-0.8 sample as illustrated by the water adsorption isotherms obtained from GCMC calculations and reported in Figure 3a for low charge sample.

Furthermore, for the $\mathrm{Na}^{+}$-saturated specimen an increase in layer charge leads to slightly higher water content, a feature that is less pronounced for $\mathrm{Cs}^{+}$-saturated samples (Figure 3b). The role of layer charge and cation nature on the organization of confined ions and water molecules can be further analyzed from their atomic concentration profiles (Figure 4). The analysis was performed on the four samples for the largest used layer-to-layer distance (i.e., $d_{001}=20 \AA$ ). At such distances, strong water layering can be observed together with complex distributions of interlayer cations (Figure 4). Indeed, the concentration profiles obtained for cations display a coexistence between fully and partially hydrated cations, also called outer-sphere and innersphere complexes, respectively. ${ }^{62}$ The presence of inner-sphere complexes for $\mathrm{Na}^{+}$and $\mathrm{Cs}^{+}$is linked to a loss of water molecules in the cation hydration shell due to contact ionic pairing with negatively charged atomic sites located at the clay surface. The fraction of inner-sphere complexes of cations can be quantified by integrating cation concentration profiles (Table 2). It 
appears to vary with both layer charge and interlayer cation nature. Such behavior was previously shown to result from the surface localization of clay electric charges that significantly modifies the variation of interfacial free energy as a function of clay period. ${ }^{41}$ As shown from Table 2, accumulation of $\mathrm{Cs}^{+}$at the clay surface drastically reduces the apparent electric charge of clay particles, thus affecting their swelling behavior. A quantification of this phenomenon can be obtained by plotting the variation of the interfacial free energy $\Delta \mathrm{F}^{\text {tot. }}$ as a function of the layerto-layer distance calculated from MD simulations. As illustrated on Figure 5, the electrostatic contribution $\left(\Delta \mathrm{F}^{\text {elec. }}\right)$ to the interfacial free energy is almost repulsive while the short-ranged Van der Waals contribution $\left(\Delta \mathrm{F}^{\mathrm{VdW}}\right)$ is always attractive. This result totally differs from predictions of the diffuse layer theory that always exhibit a net electrostatic attraction between the clay layers neutralized by their cations. ${ }^{63,64}$ The hydration of the clay layers and their neutralizing cations, neglected by the diffuse layer theory, is responsible for such a behavior. ${ }^{41}$ As displayed in Figure 5a, the free energy for Na-Sap- 0.8 showing different local minima is compatible with the coexistence of various hydrates in water-saturated conditions, including large $d_{001}$ values. This concurs with the WAXS analyses performed in the present study (Table 1) and with previous XRay diffraction measurements on low-charge natural smectite. ${ }^{40,65-67}$ Replacing interlayer $\mathrm{Na}^{+}$by $\mathrm{Cs}^{+}$cations (Figure 5b) significantly modifies the free energy variation by reducing the height of the free energy barriers that accounts for the possible coexistence of different hydrates at $298 \mathrm{~K}$. As an example, a barrier of $16 \pm 5 \mathrm{~kJ} /(\mathrm{mol}$ of unit cell $)$ is associated to the possible transition from the local minimum of the Na-Sa-0.8 sample (Figure 5a), located at $d_{001} \sim 14.5 \AA$, to the absolute minimum located at $\sim 10 \AA$. In the presence of cesium (Figure $5 b$ ) the corresponding activation energy between the local minimum, located at $d_{001} \sim 15.0 \AA$, and the same absolute minimum is reduced by a factor of about two, leading to $9 \pm 5 \mathrm{~kJ} /(\mathrm{mol}$ of unit cell), which favors 
the collapse of the layer in water-saturated conditions. Increasing the layer charge from 0.8 to 1.8 $e^{-}$per unit cell (Figures $5 \mathrm{c}$ and $\mathrm{d}$ ) further reduces the same free energy barrier characterizing the collapse of the layer. The activation energy detected for the high charge samples is indeed reduced to $12 \pm 5$ and to $8 \pm 5 \mathrm{~kJ} /$ (mol of unit cell) for Na-Sap-1.8 and Cs-Sap-1.8, respectively (Figures $5 \mathrm{c}$ and $\mathrm{d}$ ). It must be pointed out that these results must only be considered in a qualitative way in view of (i) numerical uncertainties and (ii) the empirical nature of the molecular model used to describe clay/water interfaces. More quantitative results could be obtained by using realistic quantum calculations based on DFT approximation able to reliably describe atomic charges and polarization effects in addition to dispersion forces.

Qualitative and quantitative evidences for structural disorder in Cs-Sap-x samples. The molecular simulation study qualitatively shows that increasing layer charge, or $\mathrm{Cs}^{+}-$for- $\mathrm{Na}^{+}$ interlayer exchange tends to facilitate layer collapse. Such findings are consistent with the gradual decrease with layer charge of $d_{001}$ values for Cs-Sap- $x$ samples and the increased amount of fixed $\mathrm{Cs}^{+}$in the interlayer. Still, apart from the two low charge samples (i.e. Cs-Sap-0.8 and Cs-Sap-1.0), the concomitant presence of both exchangeable and fixed $\mathrm{Cs}^{+}$remains unclear (Figure 1b). In order to get additional insights into the structure of these samples, an XRD analysis was performed on oriented samples (Figure 6). The analysis was performed at high relative humidity (i.e., $80 \% \mathrm{RH}$ ) in order to analyze the structures in conditions as close as possible from the water-saturated ones in which $\mathrm{Cs}^{+}$exchange or fixation occurs. The $d_{001}$ values obtained for these samples are reported in Table 3 and compare well with the values reported for the same samples in water-saturated conditions, excepted for Cs-Sap-1.2 sample. The use of oriented preparation enhances the intensities of $00 \ell$ reflections (Figure 6), thus allowing a 
detailed investigation of the structural order/disorder in the samples through the analysis of peak positions and shapes. For crystals composed of layers having a unique set of layer-to-layer distances (periodic structure), the $\ell \cdot d_{00 \ell}$ product is a constant for all reflections and the series of $00 \ell$ reflections is called rational $\left(\ell \cdot d_{00 \ell}=d_{001}\right)$. On Figure 6 , the theoretical positions of $00 \ell$ reflections corresponding to periodic monohydrated $\left(1 \mathrm{~W} ; d_{001}=12.7 \AA\right)$ and dehydrated ( $0 \mathrm{~W}$; $d_{001}=10.8 \AA$ ) structures are reported. For Cs-Sap-0.8 and Cs-Sap-1.0, the experimental diffraction bands match in position with the theoretical periodic $1 \mathrm{~W}$ structure. This indicates that these two samples are mostly composed by $1 \mathrm{~W}$ layers. For Cs-Sap- $x$ samples characterized by $1.4 \leq x \leq 2.0$, the experimental XRD patterns display typical diffraction features of random interstratification of $1 \mathrm{~W}$ and $0 \mathrm{~W}$ layers. Indeed, for crystals with a random interstratification of $1 \mathrm{~W}$ and $0 \mathrm{~W}$ layers, the resulting diffraction patterns display peaks in intermediate positions between those expected for periodic $1 \mathrm{~W}$ or $0 \mathrm{~W}$ structures. ${ }^{27,68}$ In addition, the resulting peak widths will depend not only on the mean coherent scattering domain size but also on the angular distance between the positions for reflections of periodic $1 \mathrm{~W}$ and $0 \mathrm{~W}$ endmembers. This diffraction effect is responsible for the loss of rationality in the series of $00 \ell$ reflections (i.e., variation in the $\ell \cdot d_{00 \ell}$ product from one reflection to another). For the samples with a layer charge $1.4 \leq x \leq 2.0$, the 001 reflection gradually migrate towards higher angles whereas the diffraction bands located at $\sim 33-34$ and $42-43^{\circ} 2 \theta$ shift towards lower angles, i.e., in direction of the theoretical positions corresponding to periodic $0 \mathrm{~W}$ structure. As far as Cs-Sap-1.2 sample is concerned, the experimental pattern displays rather sharp and well-defined $00 \ell$ reflections with positions located at equal angular distances between the reflections of periodic $1 \mathrm{~W}$ and $0 \mathrm{~W}$ endmembers (Figure 6). These diffraction features are typical of a tendency of $1 \mathrm{~W}$ and $0 \mathrm{~W}$ layers to order in the stack of layers into $1 \mathrm{~W}-0 \mathrm{~W}$ subsequences, leading to partially ordered 
interstratification. ${ }^{2}$ This qualitative analysis of $00 \ell$ reflections positions and shapes for Cs-Sap- $x$ sample series reveals that, except for the two low charge samples, the structures display significant structural disorder as evidenced by the interstratification of layers with different swelling properties. The increase in relative abundance of collapsed layers when increasing layer charge is likely responsible for the gradual shift of the $d_{001}$ values (Table 3, Figure 6) and the progressive structural trapping of interlayer $\mathrm{Cs}^{+}$cations (Figure 1). In order to further support this interpretation and to provide some quantitative data on the coexistence of hydrated and collapsed layers within the same structures, XRD profile modeling is required based on the physical description of the distribution of layers in crystals using Markovian statistics. ${ }^{30,69}$ This method was applied on three selected samples, i.e., the two endmembers Cs-Sap-0.8 and Cs-Sap2.0 as well as on sample Cs-Sap-1.2 for which a noticeable deviation from the theoretical CEC is observed (Figure 1b).

Calculated patterns are compared to experimental XRD profiles in Figure 7. The relative proportion and composition as well as the Reichweite parameter of the two MLSs used in the fitting procedure are reported in Table 4 . This table also includes the number $\mathrm{N}$ of layers in coherent scattering domain size, the layer-to-layer distances of $0 \mathrm{~W}, 1 \mathrm{~W}, 2 \mathrm{~W}$ layer types, and the overall relative contributions of the different layer types in the samples. The experimental XRD pattern of the low charge Cs-Sap-0.8 sample (Figure 7a) was reproduced considering two randomly interstratified (Reichweite parameter $=0$ ) MLSs. The first MLS (MLS\#1; Table 4) is mostly composed of $1 \mathrm{~W}$ layers and minor amounts of $2 \mathrm{~W}$ and $0 \mathrm{~W}$ layers $(2 \mathrm{~W}: 1 \mathrm{~W}: 0 \mathrm{~W}=5 / 93 / 2$, respectively), whereas the second MLS (MLS\#2; Table 4) contains the three layer types in similar proportions $(2 \mathrm{~W} / 1 \mathrm{~W} / 0 \mathrm{~W}=30 / 40 / 30)$. By combining the two MLSs in 64:36 proportion a satisfactorily fit of experimental pattern is obtained (Figure 7a). Such combination leads to an 
overall $2 \mathrm{~W} / 1 \mathrm{~W} / 0 \mathrm{~W}$ layer content of 14/74/12. For sample Cs-Sap-1.2, the two MLSs contains similar proportion of $0 \mathrm{~W}$ layers but differ by their content in $2 \mathrm{~W}$ layers and their stacking mode (Table 4, Figure 7b). Maximum degree of layer ordering (Reichweite parameter =1) was considered for MLS\#1 composed as $2 \mathrm{~W} / 1 \mathrm{~W} / 0 \mathrm{~W}=10 / 35 / 55$ (the junction probability between two neighbor $1 \mathrm{~W}$ layers in the stack referred to as $\mathrm{P}_{1 \mathrm{~W}-1 \mathrm{~W}}=0.00$ is lower than the relative abundance of $1 \mathrm{~W}$ layers, i.e., 0.35 ; Table 4, Figure $7 \mathrm{~b}$ ) in order to reproduce peak shape and intensities for the whole $00 \ell$ reflection series, in agreement with the qualitative analysis of experimental patterns (Figure 5). The second MLS only contains $1 \mathrm{~W}$ and $0 \mathrm{~W}$ layers in similar relative abundance and with random interstratification. For this sample, a satisfactorily fit was obtained when combining the two MLSs in almost equal proportions leading to an overall $2 \mathrm{~W} / 1 \mathrm{~W} / 0 \mathrm{~W}$ layer composition of 5/41/54 (Table 4, Figure 7b). The last Cs-Sap-2.0 sample displays randomly interstratified MLSs with contrasted 0W layer contents. The first MLS display an overwhelming proportion of $0 \mathrm{~W}$ layer in addition to minor proportions of $2 \mathrm{~W}$ layers $(2 \mathrm{~W} / 0 \mathrm{~W}=88 / 12$, Table 4 , Figure 7c) whereas MLS\#2 noticeable amount of $1 \mathrm{~W}$ and $2 \mathrm{~W}$ layers $(2 \mathrm{~W} / 1 \mathrm{~W} / 0 \mathrm{~W}=30 / 25 / 45)$. This optimum structure model leads to a total layer content $2 \mathrm{~W} / 1 \mathrm{~W} / 0 \mathrm{~W}=16 / 8 / 76$ for this high charge end member. Note that the origin for the relative high proportion of $2 \mathrm{~W}$ layers in this sample, similar to the proportion reported in Cs-Sap-08, remains unclear. Compared to the qualitative analysis of experimental XRD patterns, the modeling method provides additional support for the disordered nature of the structures where collapsed and hydrated layers coexist.

\section{A structural model for $\mathrm{Cs}^{+}$fixation based on heterogeneous charge distribution. Results} from XRD analysis indicate that the increase with layer charge of the proportion of collapsed layers is responsible for the gradual shift of $d_{001}$ values (Tables 1 and 3 ) and for the increased 
fixation of interlayer $\mathrm{Cs}^{+}$(Figure 1b). As an illustration, the amount of $0 \mathrm{~W}$ layers represent 12, 54 and $76 \%$ for Cs-Sap-0.8, Cs-Sap-1.2 and Cs-Sap-2.0 samples, respectively (Table 4). By considering that only $\mathrm{Cs}^{+}$in hydrated layers can be extracted from the structures, the amount of extractable $\mathrm{Cs}^{+}$can be calculated on the basis of the relative amount of hydrated layers deduced from XRD modeling and the global theoretical CEC value for a given layer charge. Such a calculation yields estimated extractable $\mathrm{Cs}^{+}$contents of $\sim 76,59$ and 46 meq per $100 \mathrm{~g}$ of air dried clay for Cs-Sap-0.8, Cs-Sap-1.2 and Cs-Sap-2.0 samples, respectively. In comparison, experimental extraction measurements lead to values of 76, 107 and 43 meq per 100g of air dried clay (Figure 1b). For the two end members, measured and calculated $\mathrm{Cs}^{+}$contents match perfectly. In contrast, for the intermediate layer charge, the calculated extractable $\mathrm{Cs}^{+}$amount is lower than the measured one. This difference can be linked to the lower $d_{001}$ value obtained for this sample at $80 \%$ RH compared to water-saturated conditions (Table 3), which suggests an overestimation of the relative amount of $0 \mathrm{~W}$ layers due to dehydration of the structure between aqueous conditions and $80 \% \mathrm{RH}$.

This study clearly evidences an increase with layer charge of nanometer-scale fixation of $\mathrm{Cs}^{+}$ that can be linked to the increase in the relative amount of collapsed layers. Still, the origin of the coexistence of both collapsed and swelling layers within the same sample remains unclear, even if simulation results reveal relatively low free energy barriers between both states. The structural effect observed could also be tentatively assigned to chemical disorder linked to a distribution of layer charge from one layer to the other. Indeed, the layer charge of a sample is a macroscopic value that does not provide any direct information on the layer charge of all particles in the sample. For natural samples, it has been shown since the 1960's that layer charge distribution 
was always heterogeneous. ${ }^{1,70-76}$ Furthermore, a recent study on synthetic samples also revealed significant charge heterogeneity in synthetic samples similar to those used in the present study. ${ }^{77}$ On this basis, let us now assume a model based on a chemical disorder in which (i) the overall sample charge is the result of a normal distribution of layers with an individual charge $x$ differing from one layer to the other and (ii) the existence of a charge limit $x_{\text {lim }}$ differentiating swelling $\left(x<x_{\text {lim }}\right)$ from collapsed $\left(x \geq x_{\text {lim }}\right)$ layers. This layer charge distribution can be defined by the function $F(x)$ according to a normal distribution:

$$
F(x)=\frac{1}{\sigma \sqrt{2 \pi}} e^{-\frac{1}{2}\left(\frac{x-\mu}{\sigma}\right)^{2}},
$$

where $\mu$ and $\sigma$ are the mean sample layer charge and the standard deviation of the distribution, respectively, and by unitary integral over $[0 ; \infty]$ interval (Figure $8 \mathrm{a}$ ). The fraction of swelling layers with a charge $x$ lower than the limit value $x_{\text {lim }}$ is defined as $P\left(x<x_{\text {lim }}\right)$ by

$$
P\left(x<x_{\text {lim }}\right)=\int_{0}^{x_{\lim }} F(x) d x
$$

For the calculation of extractable $\mathrm{Cs}^{+}$amount to be compared to experimental data, correction from the variation of charge from individual layers needs to be considered. This can be achieved through the analysis of the first momentum of $F(x)$ function. The entity corresponding to the overall amount of layer charge associated to exchangeable $\mathrm{Cs}^{+} L C\left(x<x_{\text {lim }}\right)\left(\right.$ per $\left.\mathrm{O}_{20}(\mathrm{OH})_{4}\right)$ is then defined as:

$$
L C\left(x<x_{\text {lim }}\right)=\int_{0}^{x_{\lim }} x F(x) d x
$$

with $\int_{0}^{\infty} x F(x) d x=\mu$. The predicted extractable $\mathrm{Cs}^{+}$amount is then obtained by the relation:

$$
q_{C S^{+}}=\frac{L C\left(x<x_{l i m}\right)}{\mu} C E C^{T},
$$


where $C E C^{T}$ is the theoretical CEC. In this model, the parameter $\mu$ is known and varies from 0.8 to $2.0 / \mathrm{O}_{20}(\mathrm{OH})_{4}$ for the whole sample series, whereas the two other parameters $\sigma$ and $x_{\text {lim }}$ can be obtained from a best-fit of the experimental data reported in Figure 1b. As illustrated in Figure 8b, input values $x_{\text {lim }}=1.65 / \mathrm{O}_{20}(\mathrm{OH})_{4}$ and $\sigma=0.34 / \mathrm{O}_{20}(\mathrm{OH})_{4}$ lead to a very good agreement between experimental and predicted extractable $q_{C S^{+}}$amounts. The $x_{\text {lim }}$ value is slightly above the layer charge of 1.4 per $\mathrm{O}_{20}(\mathrm{OH})_{4}$ corresponding to the structural configuration where each $\mathrm{OH}$ group of the octahedral sheet is exposed to at least one Al substitution in the tetrahedral sheet. ${ }^{71}$ This configuration was also shown to be responsible for the organization of interlayer cations into a two-dimensional ordered network. ${ }^{19}$ Both effects likely imply stronger $\mathrm{Cs}^{+}$ interaction with the clay surface, in agreement with results from molecular simulations (Figure 4 and 5), and may be at the origin of layer collapse. Regarding the standard deviation of the distribution, the value of parameter $\sigma$ at $\sim 0.34$ per $\mathrm{O}_{20}(\mathrm{OH})_{4}$ can be compared to previously reported results on the distribution of structural $\mathrm{Si}$ in smectite individual layers ${ }^{77}$ using X-ray photo-emission electron microscopy. Si X-ray photoelectron spectroscopy (XPS) spectra of clay minerals were obtained for a large set of individual particles in a given sample to reveal the distribution in tetrahedral layer charge. The used sample set included the synthetic saponite samples with layer charges of $0.8 / \mathrm{O}_{20}(\mathrm{OH})_{4}$ and $1.3 / \mathrm{O}_{20}(\mathrm{OH})_{4}{ }^{77}$ The use of three components was needed to reach a satisfactory fit of raw Si XPS spectra. These components were assigned to $\mathrm{SiO}_{4}$ tetrahedron with zero, one, or two oxygen atoms linked to aluminum in the tetrahedral sheet. The authors also reported the relative proportions of these different contributions for numerous layers investigated (up to $\sim 60$ and $\sim 110$ for samples with mean layer charge of 0.8 and $1.3 / \mathrm{O}_{20}(\mathrm{OH})_{4}$, respectively; see Figure 5 in Vantelon et al. $\left.{ }^{77}\right)$. These data were fitted according to a normal distribution using Eq. (3) leading for both samples to a standard deviation of 0.24 per 
$\mathrm{O}_{20}(\mathrm{OH})_{4}$. Interestingly, such a value is in fair agreement with the value resulting from the bestfit approach using the above-described model (i.e., $\sigma=0.34 / \mathrm{O}_{20}(\mathrm{OH})_{4}$, Figure $8 \mathrm{~b}$ ).

Despite its simplicity, such a toy-model based on heterogeneous layer charge distribution provides an excellent estimate of the amount of extractable (and fixed) $\mathrm{Cs}^{+}$in smectite as a function of the mean layer charge. Furthermore, this model opens the way towards a better understanding of $\mathrm{Cs}^{+}$extractability in natural vermiculite samples. Indeed, as shown by Dzene et al. ${ }^{58,59}$, interlayer $\mathrm{Cs}^{+}$is not exchangeable in vermiculite with a mean layer charge of $\sim 1.6 / \mathrm{O}_{20}(\mathrm{OH})_{4}$. For this layer charge in the case of saponite, both the model and experimental value lead to a $40 \%$ proportion of extractable $\mathrm{Cs}^{+}$. The strong difference in behavior between saponite and vermiculite could be tentatively assigned to two possible effects. First, the standard deviation may differ between natural vermiculite and the synthetic saponite sample studied here. By considering a more homogeneous charge distribution with parameter $\sigma<0.04$ per $\mathrm{O}_{20}(\mathrm{OH})_{4}$, the model would predict the proportion of extractable $\mathrm{Cs}^{+}$to decrease down to $<1 \%$. Such an explanation appears, however, rather unlikely as natural samples are known to display heterogeneous charge distribution. The second explanation would be linked to enhanced local interaction between $\mathrm{Cs}^{+}$cations and the negative layer surface. It is worth pointing out that the structural formula of the natural vermiculite sample studied by Dzene et al. ${ }^{58,59,78}$, inter $\left[M^{+}{ }_{1.64}\right]^{\text {oct }}\left[\mathrm{Mg}_{4.92} \mathrm{Al}_{0.59} \mathrm{Fe}_{0.43} \mathrm{Ti}_{0.04}\right]^{\text {tet }}\left[\mathrm{Si}_{5.66} \mathrm{Al}_{2.34}\right] \mathrm{O}_{20}(\mathrm{OH})_{4}{ }^{79}$, corresponds to a very high tetrahedral negative layer charge (i.e., of $\left.2.34 / \mathrm{O}_{20}(\mathrm{OH})_{4}\right)$ partially balanced by positive octahedral layer charge (i.e., of $0.7 / \mathrm{O}_{20}(\mathrm{OH})_{4}$ ) due to $\mathrm{Al}^{3+} / \mathrm{Fe}^{3+}-$ for- $\mathrm{Mg}^{2+}$ substitution. By considering the vermiculite tetrahedral layer charge (i.e., $\left.2.34 / \mathrm{O}_{20}(\mathrm{OH})_{4}\right)$ only, using the model with the same $\sigma$ parameter as that used for saponite samples, the calculated amount of extractable $\mathrm{Cs}^{+}$becomes negligible. This strongly suggests that tetrahedral layer charge and 
therefore local electrostatic interactions are of prime importance in the control of $\mathrm{Cs}^{+}$exchange in swelling clay minerals. This hypothesis deserves further confirmation as it could be extremely useful to predict the fate and transfer of various pollutants in natural clay-rich soils.

\section{CONCLUSION}

The combined use of chemical extraction measurements and structure analysis confirms that layer charge of swelling clay minerals is an important parameter controlling $\mathrm{Cs}^{+}$fixation. The observed increase in $\mathrm{Cs}^{+}$fixation with increasing layer charge could indeed be quantitatively linked to a structural trapping of the cation resulting from dehydration of the interlayer space and subsequent collapse. Even for synthetic samples with well-controlled chemistry, charge distribution heterogeneity from one layer to another appears as a key factor to explain the evolution of $\mathrm{Cs}^{+}$exchangeability with layer charge. This suggests that charge distribution heterogeneity should be considered in cases where partial cationic fixation in the interlayer is observed. This could be particularly important for predicting pollutant migration in natural media due to the wide range of mineral layer charge commonly encountered in such systems. In that regard, the extension of the methodology used here to other types of smectite samples with similar chemistry but different charge distribution ${ }^{80,81}$ or to other types of smectite samples with isomorphic substitutions located in the octahedral sheet ${ }^{31}$ could be used to further refine the model of $\mathrm{Cs}^{+}$reactivity. If validated, this model of charge distribution could be tentatively extended to the interpretation of commonly observed hydration heterogeneity in smectite resulting from coexistence of layers with different hydration states for a given relative humidity and a given interlayer cation. . $^{15,19,31}$ 


\section{AUTHOR INFORMATION}

\section{Corresponding Author}

*liva.dzene@univ-poitiers.fr

\section{Present Addresses}

† Institut de Science des Matériaux de Mulhouse (IS2M) - Université de Haute Alsace/CNRS :

UMR7228 - 15 rue Jean Starcky, 68057 Mulhouse Cedex, France

$\dagger \dagger$ GeoRessources - Université de Lorraine, CNRS : UMR7359, CREGU - BP 70239, F-54506

Vandœuvre-lès-Nancy, France

\section{ACKNOWLEDGMENT}

The results presented are part of the PhD thesis of Liva Dzene at the University of Poitiers granted by the "Ministère de l'Enseignement Supérieur et de la Recherche", France. The authors wish to acknowledge synchrotron Soleil for provision of beamtime on the SWING beamline and Dr. Patrick Davidson (Laboratoire de Physique des Solides, Orsay, France) for his contribution and expertise in WAXS experiments. The CNRS interdisciplinary “défi Needs", through its “MiPor" program (Projects MPDYN \& TRANSREAC), and the French national program EC2CO-Biohefect (Project DIFFMATARG) are acknowledged for providing financial support for this study.

\section{REFERENCES}

(1) Laird, D. A. Influence of Layer Charge on Swelling of Smectites. Appl. Clay Sci. 2006, 34 (1-4), 74-87.

(2) Ferrage, E. Investigation of the Interlayer Organization of Water and Ions in Smectite 
from the Combined Use of Diffraction Experiments and Molecular Simulations. A Review of Methodology, Applications, and Perspectives. Clays Clay Miner. 2016, 64 (4), 348 LP373.

(3) Churchman, G. J.; Gates, W. P.; Theng, B. K. G.; Yuan, G. Clays and Clay Minerals for Pollution Control. In Handbook of Clay Science; Bergaya, F., Theng, B. K. G., Lagaly, G., Eds.; Elsevier, 2006; Vol. 1, pp 625-675.

(4) Strebl, F.; Gerzabek, M. H.; Bossew, P.; Kienzl, K. Distribution of Radiocaesium in an Austrian Forest Stand. Sci. Total Environ. 1999, 226 (1), 75-83.

(5) Yasunari, T. J.; Stohl, A.; Hayano, R. S.; Burkhart, J. F.; Eckhardt, S.; Yasunari, T. Cesium-137 Deposition and Contamination of Japanese Soils due to the Fukushima Nuclear Accident. Proc. Natl. Acad. Sci. 2011, 108 (49), 19530-19534.

(6) Francis, C. W.; Brinkley, F. S. Preferential Adsorption of 137Cs to Micaceous Minerals in Contaminated Freshwater Sediment. Nature 1976, 260, 511-513.

(7) Cremers, A.; Elsen, A.; De Preter, P.; Maes, A. Quantitative Analysis of Radiocaesium Retention in Soils. Nature 1988, 335 (6187), 247-249.

(8) Sawhney, B. L. Selective Sorption and Fixation of Cations by Clay Minerals: A Review. Clays Clay Miner. 1972, 20, 93-100.

(9) Mukai, H.; Hatta, T.; Kitazawa, H.; Yamada, H.; Yaita, T.; Kogure, T. Speciation of Radioactive Soil Particles in the Fukushima Contaminated Area by IP Autoradiography and Microanalyses. Environ. Sci. Technol. 2014, 48 (22), 13053-13059. 
(10) Iijima, K.; Tomura, T.; Shoji, Y. Reversibility and Modeling of Adsorption Behavior of Cesium Ions on Colloidal Montmorillonite Particles. Appl. Clay Sci. 2010, 49 (3), $262-$ 268.

(11) de la Calle, C.; Suquet, H. Vermiculite. In Hydrous Phyllosilicates (Exclusive of Micas); Bailey, S. W., Ed.; Mineralogical Society of America: Madison, Wisconsin, USA, 1988; pp 455-496.

(12) Kogure, T.; Morimoto, K.; Tamura, K.; Sato, H.; Yamagishi, A. XRD and HRTEM Evidence for Fixation of Cesium Ions in Vermiculite Clay. Chem. Lett. 2012, 41 (4), 380382.

(13) Christidis, G. E. The Concept of Layer Charge of Smectites and Its Implications for Important Smectite-Water Properties. In Layered mineral structures and their Application in Advanced Technologies; Brigatti, M. F., Mottana, A., Eds.; Mineralogical Society: London, 2011; pp 237-258.

(14) Michot, L. J.; Villiéras, F. Assessment of Surface Energetic Heterogeneity of Synthetic Na-Saponites. The Role of Layer Charge. Clay Miner. 2002, 37, 39-57.

(15) Ferrage, E.; Lanson, B.; Michot, L. J.; Robert, J. L. Hydration Properties and Interlayer Organization of Water and Ions in Synthetic Na-Smectite with Tetrahedral Layer Charge. Part 1. Results from X-Ray Diffraction Profile Modeling. J. Phys. Chem. C 2010, 114 (10), 4515-4526.

(16) Ferrage, E.; Sakharov, B. A.; Michot, L. J.; Delville, A.; Bauer, A.; Lanson, B.; Grangeon, S.; Frapper, G.; Jiménez-Ruiz, M.; Cuello, G. J. Hydration Properties and Interlayer 
Organization of Water and Ions in Synthetic Na-Smectite with Tetrahedral Layer Charge.

Part 2. Toward a Precise Coupling between Molecular Simulations and Diffraction Data. J. Phys. Chem. C 2011, 115 (5), 1867-1881.

(17) Michot, L. J.; Delville, A.; Humbert, B.; Plazanet, M.; Levitz, P. Diffusion of Water in a Synthetic Clay with Tetrahedral Charges by Combined Neutron Time-of-Flight Measurements and Molecular Dynamics Simulations. J. Phys. Chem. C 2007, 111 (27), 9818-9831.

(18) Michot, L. J.; Ferrage, E.; Jiménez-Ruiz, M.; Boehm, M.; Delville, A. Anisotropic Features of Water and Ion Dynamics in Synthetic Na- and Ca-Smectites with Tetrahedral Layer Charge. A Combined Quasi-Elastic Neutron-Scattering and Molecular Dynamics Simulations Study. J. Phys. Chem. C 2012, 116 (31), 16619-16633.

(19) Dazas, B.; Lanson, B.; Delville, A.; Robert, J.-L.; Komarneni, S.; Michot, L. J.; Ferrage, E. Influence of Tetrahedral Layer Charge on the Organization of Interlayer Water and Ions in Synthetic Na-Saturated Smectites. J. Phys. Chem. C 2015, 119 (8), 4158-4172.

(20) Jiménez-Ruiz, M.; Ferrage, E.; Delville, A.; Michot, L. J. Anisotropy on the Collective Dynamics of Water Confined in Swelling Clay Minerals. J. Phys. Chem. A 2012, 116 (10), 2379-2387.

(21) Michot, L. J.; Ferrage, E.; Delville, A.; Jiménez-Ruiz, M. Influence of Layer Charge, Hydration State and Cation Nature on the Collective Dynamics of Interlayer Water in Synthetic Swelling Clay Minerals. Appl. Clay Sci. 2016, 119, 375-384.

(22) Jiménez-Ruiz, M.; Ferrage, E.; Blanchard, M.; Fernandez-Castanon, J.; Delville, A.; 
Johnson, M. R.; Michot, L. J. Combination of Inelastic Neutron Scattering Experiments and $\mathrm{Ab}$ Initio Quantum Calculations for the Study of the Hydration Properties of Oriented Saponites. J. Phys. Chem. C 2017, 121 (9), 5029-5040.

(23) Bergaya, F.; Lagaly, G. Purification of Natural Clays. In Handbook of Clay Science Fundamentals; Bergaya, F., Lagaly, G., Eds.; Elsevier, 2013; Vol. 5, pp 213-221.

(24) Sakharov, B. A.; Naumov, A. S.; Drits, V. A. X-Ray Intensities Scattered by Layer Structures with Short-Range Ordering Parameters $\mathrm{S} \geq 1$ and $\mathrm{G} \geq 1$. Dokl. Akad. Nauk $1982,265,871-874$.

(25) Sakharov, B. A.; Naumov, A. S.; Drits, V. A. X-Ray Diffraction by Mixed-Layer Structures with Random Distribution of Stacking Faults. Dokl. Akad. Nauk 1982, 265, 339-343.

(26) Sakharov, B. A.; Naumov, A. S.; Drits, V. A. X-Ray Scattering by Defect Layer Structures. Kristallografia 1983, 28, 951-958.

(27) Moore, D. M.; Reynolds, R. C. J. X-Ray Diffraction and the Identification and Analysis of Clay Minerals; Oxford University Press: Oxford, 1997.

(28) Drits, V. A.; Srodon, J.; Eberl, D. D. XRD Measurement of Mean Crystallite Tickness of Illite and Illite/smectite: Reappraisal of the Kubler Index and the Scherrer Equation. Clays Clay Miner. 1997, 45, 461-475.

(29) Ferrage, E.; Lanson, B.; Sakharov, B. A.; Drits, V. A. Investigation of Smectite Hydration Properties by Modeling Experimental X-Ray Diffraction Patterns: Part I. Montmorillonite 
Hydration Properties. Am. Mineral. 2005, 90 (8-9), 1358-1374.

(30) Sakharov, B. A.; Lanson, B. X-Ray Identification of Mixed-Layer Structures. Modelling of Diffraction Effects. In Handbook of Clay Science; Bergaya, F., Lagaly, G., Eds.; Elsevier, 2013; pp 51-135.

(31) Dazas, B.; Lanson, B.; Breu, J.; Robert, J. L.; Pelletier, M.; Ferrage, E. Smectite Fluorination and Its Impact on Interlayer Water Content and Structure: A Way to Fine Tune the Hydrophilicity of Clay Surfaces? Microporous Mesoporous Mater. 2013, 181, $233-247$.

(32) Dazas, B.; Ferrage, E.; Delville, A.; Lanson, B. Interlayer Structure Model of TriHydrated Low-Charge Smectite by X-Ray Diffraction and Monte Carlo Modeling in the Grand Canonical Ensemble. Am. Mineral. 2014, 99 (8-9), 1724-1735.

(33) Ferrage, E.; Lanson, B.; Michot, L. J.; Robert, J. L. Hydration Properties and Interlayer Organization of Water and Ions in Synthetic Na-Smectite with Tetrahedral Layer Charge. Part 1. Results from X-Ray Diffraction Profile Modeling. J. Phys. Chem. C 2010, 114, $4515-4526$.

(34) Howard, S. A.; Preston, K. D. Profile Fitting of Powder Diffraction Patterns. Rev. Mineral. Geochemistry 1989, 20 (1), 217-275.

(35) Norrish, K. The Swelling of Montmorillonite. Discuss. Faraday Soc. 1954, 18 (0), 120134.

(36) Israelachvili, J. Intermolecular and Surface Forces; Academic Press: New York, 1985. 
(37) Dubois, M.; Zemb, T.; Belloni, L.; Delville, A.; Levitz, P.; Setton, R. Osmotic Pressure and Salt Exclusion in Electrostatically Swollen Lamellar Phases. J. Chem. Phys. 1992, 96 (3), 2278-2286.

(38) Delville, A.; Gasmi, N.; Pellenq, R. J. M.; Caillol, J. M.; Van Damme, H. Correlations between the Stability of Charged Interfaces and Ionic Exchange Capacity: A Monte Carlo Study. Langmuir 1998, 14 (18), 5077-5082.

(39) Carley, D. D. Radial Distributions of Ions for a Primitive Model of an Electrolyte Solution. J. Chem. Phys. 1967, 46 (10), 3783-3788.

(40) Norrish, K. The Swelling of Montmorillonite. Discuss. Faraday Soc. 1954, 18, 120-134.

(41) Delville, A. Beyond the Diffuse Layer Theory: A Molecular Analysis of the Structural, Dynamical, and Mechanical Properties of Charged Solid/Liquid Interfaces. J. Phys. Chem. C 2013, 117 (28), 14558-14569.

(42) Cygan, R. T.; Liang, J.-J.; Kalinichev, A. G. Molecular Models of Hydroxide, Oxyhydroxide, and Clay Phases and the Development of a General Force Field. J. Phys. Chem. B 2004, 108 (4), 1255-1266.

(43) Berendsen, H. J. C.; Grigera, J. R.; Straatsma, T. P. The Missing Term in Effective Pair Potentials. J. Phys. Chem. 1987, 91 (24), 6269-6271.

(44) Adams, D. J. Grand Canonical Ensemble Monte Carlo for a Lennard-Jones Fluid. Mol. Phys. 1975, 29 (1), 307-311.

(45) Allen, M. P.; Tildesley, D. J. Computer Simulation of Liquids; Oxford Science 
Publications: Oxford, 1994.

(46) Hummer, G. The Numerical Accuracy of Truncated Ewald Sums for Periodic Systems with Long-Range Coulomb Interactions. Chem. Phys. Lett. 1995, 235 (3), 297-302.

(47) Heyes, D. M. Pressure Tensor of Partial-Charge and Point-Dipole Lattices with Bulk and Surface Geometries. Phys. Rev. B 1994, 49 (2), 755-764.

(48) Berendsen, H. J. C.; Postma, J. P. M.; van Gunsteren, W. F.; DiNola, A.; Haak, J. R. Molecular Dynamics with Coupling to an External Bath. J. Chem. Phys. 1984, 81 (8), 3684-3690.

(49) Hansen, J. P.; McDonald, I. R. Theory of Simple Liquids; Academic Press: London, 1986.

(50) Delville, A. Structure and Properties of Confined Liquids: A Molecular Model of the Clay-Water Interface. J. Phys. Chem. 1993, 97 (38), 9703-9712.

(51) Shroll, R. M.; Smith, D. E. Molecular Dynamics Simulations in the Grand Canonical Ensemble: Application to Clay Mineral Swelling. J. Chem. Phys. 1999, 111 (19), 90259033.

(52) Tambach, T. J.; Hensen, E. J. M.; Smit, B. Molecular Simulations of Swelling Clay Minerals. J. Phys. Chem. B 2004, 108 (23), 7586-7596.

(53) Tambach, T. J.; Bolhuis, P. G.; Hensen, E. J. M.; Smit, B. Hysteresis in Clay Swelling Induced by Hydrogen Bonding: Accurate Prediction of Swelling States. Langmuir 2006, $22,1223-1234$.

(54) Ebrahimi, D.; Whittle, A. J.; Pellenq, R. J.-M. Mesoscale Properties of Clay Aggregates 
from Potential of Mean Force Representation of Interactions between Nanoplatelets. $J$. Chem. Phys. 2014, 140 (15), 154309.

(55) Zwanzig, R. W. High- Temperature Equation of State by a Perturbation Method. I. Nonpolar Gases. J. Chem. Phys. 1954, 22 (8), 1420-1426.

(56) Bennett, C. H. Efficient Estimation of Free Energy Differences from Monte Carlo Data. $J$. Comput. Phys. 1976, 22 (2), 245-268.

(57) Pelletier, M.; Michot, L. J.; Humbert, B.; Barr??s, O.; D’Espinose de la Caillerie, J. B.; Robert, J. L. Influence of Layer Charge on the Hydroxyl Stretching of Trioctahedral Clay Minerals: A Vibrational Study of Synthetic Na- and K-Saponites. Am. Mineral. 2003, 88 (11-12 PART 1), 1801-1808.

Dzene, L.; Tertre, E.; Hubert, F.; Ferrage, E. Nature of the Sites Involved in the Process of Cesium Desorption from Vermiculite. J. Colloid Interface Sci. 2015, 455, 254-260.

Dzene, L.; Ferrage, E.; Viennet, J.-C.; Tertre, E.; Hubert, F. Crystal Structure Control of Aluminized Clay Minerals on the Mobility of Caesium in Contaminated Soil Environments. Sci. Rep. 2017, 7, 43187.

(60) Melkior, T.; Gaucher, E. C.; Brouard, C.; Yahiaoui, S.; Thoby, D.; Clinard, C.; Ferrage, E.; Guyonnet, D.; Tournassat, C.; Coelho, D. Na+ and HTO Diffusion in Compacted Bentonite: Effect of Surface Chemistry and Related Texture. J. Hydrol. 2009, 370 (1-4), 9-20.

(61) Suquet, H. Propriétés de Gonflement et Structure de La Saponite. Comparaison Avec La 
Vermiculite., Université de Pierre et Marie Curie, Paris 6, 1978.

(62) Bourg, I. C.; Sposito, G. Molecular Dynamics Simulations of the Electrical Double Layer on Smectite Surfaces Contacting Concentrated Mixed Electrolyte (NaCl-CaCl2) Solutions. J. Colloid Interface Sci. 2011, 360 (2), 701-715.

(63) Pellenq, R. J.-M.; Caillol, J. M.; Delville, A. Electrostatic Attraction between Two Charged Surfaces: A (N,V,T) Monte Carlo Simulation. J. Phys. Chem. B 1997, 101 (42), 8584-8594.

(64) Delville, A.; Pellenq, R. J.-M.; Caillol, J. M. A Monte Carlo (N,V,T) Study of the Stability of Charged Interfaces: A Simulation on a Hypersphere. J. Chem. Phys. 1997, 106 (17), $7275-7285$.

(65) Abend, S.; Lagaly, G. Sol-gel Transitions of Sodium Montmorillonite Dispersions. Appl. Clay Sci. 2000, 16 (3-4), 201-227.

(66) Michot, L. J.; Bihannic, I.; Porsch, K.; Maddi, S.; Baravian, C.; Mougel, J.; Levitz, P. Phase Diagrams of Wyoming Na-Montmorillonite Clay. Influence of Particle Anisotropy. Langmuir 2004, 20 (25), 10829-10837.

(67) Lagaly, G.; Dékány, I. Colloid Clay Science. In Handbook of Clay Science Fundamentals; Bergaya, F., Lagaly, G., Eds.; Elsevier, 2013; Vol. 5, pp 243-345.

(68) Méring, J. L’intérférence Des Rayons X Dans Les Systemes À Stratification Désordonée. Acta Crystallogr. 1949, 2 (6), 371-377.

(69) Drits, V. A.; Tchoubar, C. X-Ray Diffraction by Disordered Lamellar Structures; 
Springer-Verlag: Berlin, Heidelberg, 1990.

(70) Stanjek, H.; Friedrich, R. The Determination of Layer Charge by Curve-Fitting of Lorentz- and Polarization-Corrected X-Ray Diagrams. Clay Miner. 1986, 21, 183-190.

(71) Pelletier, M.; Michot, L. J.; Humbert, B.; Barrès, O.; D’Espinose de la Caillerie, J. B.; Robert, J. L. Influence of Layer Charge on the Hydroxyl Stretching of Trioctahedral Clay Minerals: A Vibrational Study of Synthetic Na- and K-Saponites. Am. Mineral. 2003, 88 , $1801-1808$.

(72) Weiss, A.; Kantner, I. Uber Eine Einfache Moglichkeit Zur Abschatzung Der Schichtladung Glimmerartiger Schichtsilicate. Zeitschrift für Naturforsch. B 1960, 15 (b), 804-807.

(73) Lagaly, G. Characterization of Clays by Organic Compounds. Clay Miner. 1981, 16, 121.

(74) Lagaly, G. Layer Charge Determination by Alkylammonium Ions. In Layer Charge Characteristics of 2:1 Silicate Clay Minerals; Mermut, A. R., Ed.; 1994.

(75) Lagaly, G. Layer Charge Heterogeneity in Vermiculites. Clays Clay Miner. 1982, 30 (3), $215-222$.

(76) Lagaly, G.; Gonzalez, M. F.; Weiss, A. Problems in Layer-Charge Determination of Montmorillonites. Clay Miner. 1976, 11, 173-188.

(77) Vantelon, D.; Belkhou, R.; Bihannic, I.; Michot, L. J.; Montargès-Pelletier, E.; Robert, J. L. An XPEEM Study of Structural Cation Distribution in Swelling Clays. I. Synthetic 
Trioctahedral Smectites. Phys. Chem. Miner. 2009, 36 (10), 593-602.

(78) Dzene, L.; Ferrage, E.; Hubert, F.; Delville, A.; Tertre, E. Experimental Evidence of the Contrasting Reactivity of External vs . Interlayer Adsorption Sites on Swelling Clay Minerals : The Case of Sr $2+$-for-Ca 2 + Exchange in Vermiculite. Appl. Clay Sci. 2016.

(79) Arguelles, A.; Leoni, M.; Blanco, J. A.; Marcos, C. Semi-Ordered Crystalline Structure of the Santa Olalla Vermiculite Inferred from X-Ray Powder Diffraction. Am. Mineral. 2010, $95(1), 126-134$.

(80) Yamada, H.; Nakazawa, H.; Hashizume, H.; Shimomura, S.; Watanabe, T. Hydration Behavior of Na-Smectite Crystals Synthesized at High Pressure and High Temperature. Clays Clay Miner. 1994, 42 (1), 77-80.

(81) Tamura, K.; Yamada, H.; Nakazawa, H. Stepwise Hydration of High-Quality Synthetic Smectite with Various Cations. Clays Clay Miner. 2000, 48 (3), 400-404. 
Table of Contents (TOC) Graphic

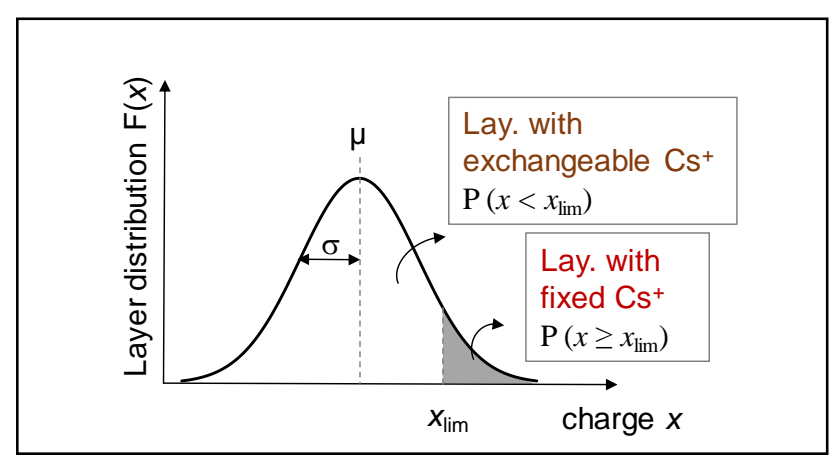


Table 1. Experimental $d_{001}$ values (in $\AA$ ) of Na-Sap- $x$ and Cs-Sap- $x$ sample series in watersaturated conditions from WAXS and SAXS measurements.

\begin{tabular}{|l|l|l|l|l|l|l|l|}
\hline$x / \mathrm{O}_{20}(\mathrm{OH})_{4}$ & 0.8 & 1.0 & 1.2 & 1.4 & \multicolumn{1}{c|}{1.6} & 1.8 & 2.0 \\
\hline Na-Sap- $\boldsymbol{x}$ & 336 & 15.1 & 15.1 & 15.1 & 15.1 & 14.9 & 14.7 \\
\hline Cs-Sap- $\boldsymbol{x}$ & 12.5 & 12.5 & 12.5 & 12.0 & 12.0 & 11.8 & 11.6 \\
\hline
\end{tabular}

Table 2. Influence of the layer charge and the nature of the cation on the fraction (in \%) of innersphere cation complexes obtained from GCMC simulations on samples with layer-to-layer distances of $20 \AA$.

\begin{tabular}{|l|c|}
\hline Sample & $\begin{array}{l}\text { Fraction of inner-sphere } \\
\text { complexes (\%) }\end{array}$ \\
\hline Na-Sap-0.8 & $37 \pm 2$ \\
\hline Na-Sap-1.8 & $72 \pm 2$ \\
\hline Cs-Sap-0.8 & $50 \pm 2$ \\
\hline Cs-Sap-1.8 & $100 \%$ \\
\hline
\end{tabular}

Table 3. Experimental $d_{001}$ values (in $\AA$ ) of Cs-Sap- $x$ sample series in water-saturated conditions (same values as in Table 1) and at $80 \%$ relative humidity.

\begin{tabular}{|l|l|l|l|l|l|l|l|}
\hline$x / \mathrm{O}_{20}(\mathrm{OH})_{4}$ & 0.8 & 1.0 & 1.2 & 1.4 & 1.6 & 1.8 & 2.0 \\
\hline Cs-Sap- $x$ in water & 12.5 & 12.5 & 12.5 & 12.0 & 12.0 & 11.8 & 11.6 \\
\hline Cs-Sap- $x$ at 80\% RH & 12.7 & 12.5 & 11.6 & 12.0 & 12.1 & 12.0 & 11.7 \\
\hline
\end{tabular}


Table 4. Structural parameters used to reproduce experimental X-ray diffraction patterns of Cs-

Sap-0.8, Cs-Sap-1.2, and Cs-Sap-2.0 samples.

\begin{tabular}{|c|c|c|c|c|}
\hline \multicolumn{2}{|c|}{ Sample } & Cs-Sap-0.8 & Cs-Sap-1.2 & Cs-Sap-2.0 \\
\hline \multirow{4}{*}{ MLS\#1 } & Rel. Cont. $(\%)^{\mathrm{a}}$ & 64 & 51 & 69 \\
\hline & $2 \mathrm{~W} / 1 \mathrm{~W} / 0 \mathrm{~W}^{\mathrm{b}}$ & $5 / 93 / 2$ & $10 / 35 / 55$ & $10 / 0 / 90$ \\
\hline & CSD size $^{\mathrm{c}}$ & 9.8 & 25 & 7 \\
\hline & $\begin{array}{l}\text { Reichweite } \\
\text { parameter \& } \\
\text { junction } \\
\text { probabilities }^{\mathrm{d}} \\
\end{array}$ & R0 & $\begin{array}{l}\mathrm{R} 1 \\
\mathrm{P}_{1 \mathrm{~W}-1 \mathrm{~W}}=0\end{array}$ & R0 \\
\hline \multirow{4}{*}{ MLS\#2 } & Rel. Cont. $(\%)^{\mathrm{a}}$ & 36 & 49 & 31 \\
\hline & $2 \mathrm{~W} / 1 \mathrm{~W} / 0 \mathrm{~W}^{\mathrm{b}}$ & $30 / 40 / 30$ & $0 / 47 / 53$ & $30 / 25 / 45$ \\
\hline & CSD size $^{c}$ & 9.8 & 25 & 20 \\
\hline & $\begin{array}{l}\text { Reichweite } \\
\text { parameter }\end{array}$ & R0 & R0 & R0 \\
\hline $\begin{array}{l}\text { Total layer } \\
\text { abundance }\end{array}$ & $2 \mathrm{~W} / 1 \mathrm{~W} / 0 \mathrm{~W}$ & $14 / 74 / 12$ & $5 / 41 / 54$ & $16 / 8 / 76$ \\
\hline \multirow{3}{*}{$\begin{array}{l}\text { Layer-to- } \\
\text { layer } \\
\text { distances }^{\mathrm{f}}\end{array}$} & $2 \mathrm{~W}$ & 14.60 & 14.60 & 14.70 \\
\hline & $1 \mathrm{~W}$ & 12.59 & 12.56 & 12.20 \\
\hline & $0 \mathrm{~W}$ & 10.71 & 10.68 & 10.70 \\
\hline \multicolumn{5}{|c|}{$\begin{array}{l}\text { Relative contributions of the different mixed-layer structures (MLS) to the } \\
\text { diffracted intensity. }{ }^{\mathrm{b}} \text { Relative proportions of the different layer types in these } \\
\text { contributions. } 2 \mathrm{~W}, 1 \mathrm{~W} \text {, and } 0 \mathrm{~W} \text { stand for bihydrated, monohydrated, and } \\
\text { dehydrated layers, respectively. }{ }^{c} \text { Mean size of the coherent scattering } \\
\text { domains along the } \mathrm{c}^{*} \text { axis (in layers). }{ }^{\mathrm{d}} \text { Reichweite parameter }(\mathrm{R} 0=\text { randomly } \\
\text { interstratified structure; } \mathrm{P}_{1 \mathrm{~W}-1 \mathrm{~W} \text { : junction probability between two neighboring }} \\
1 \mathrm{~W} \text { layers, respectively). }{ }^{\mathrm{e}} \text { The total relative contributions of } 2 \mathrm{~W}, 1 \mathrm{~W} \text {, and } \\
0 \mathrm{~W} \text { layer types in the samples. }{ }^{\mathrm{f}} \text { Layer-to-layer distances for } 2 \mathrm{~W}, 1 \mathrm{~W} \text {, and } \\
0 \mathrm{~W} \text { layers in } \AA \text {. }\end{array}$} \\
\hline
\end{tabular}



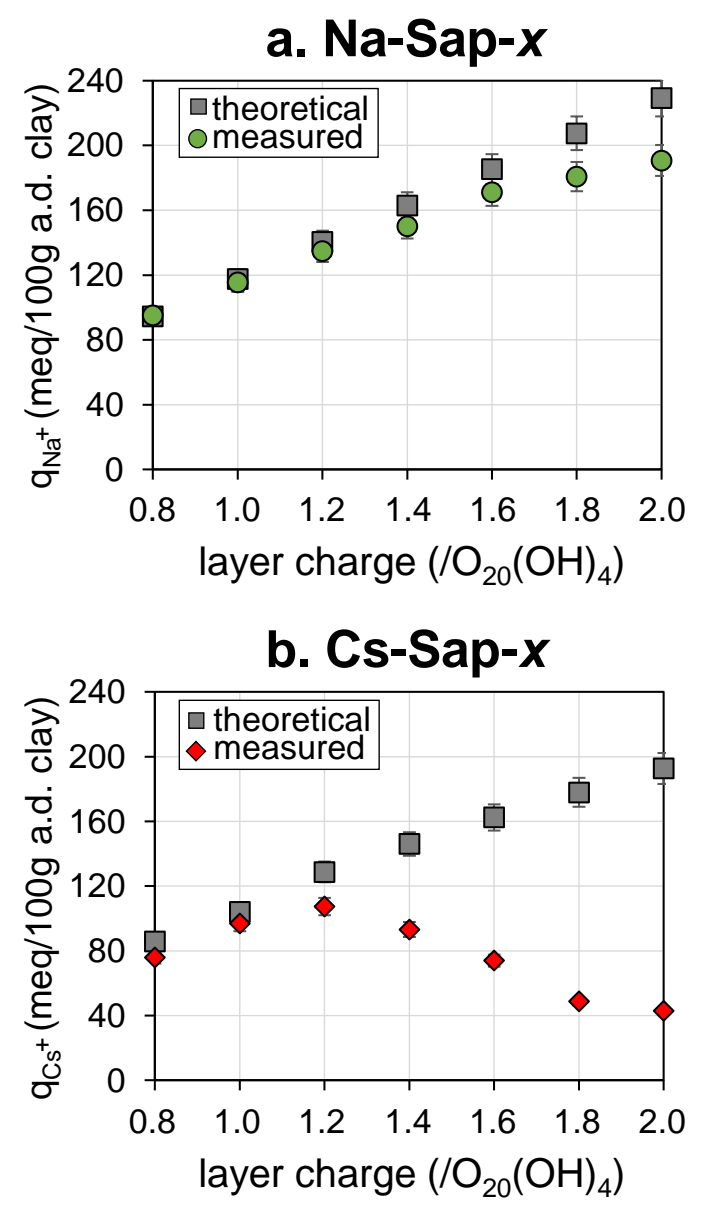

Figure 1. Comparison between theoretical cation exchange capacity and experimentally measured amount of extractable interlayer (a) $\mathrm{Na}^{+}$and (b) $\mathrm{Cs}^{+}$(in meq per 100g of air-dried clay) as a function of layer charge for Na-Sap- $x$ and Cs-Sap- $x$ sample series, respectively. 

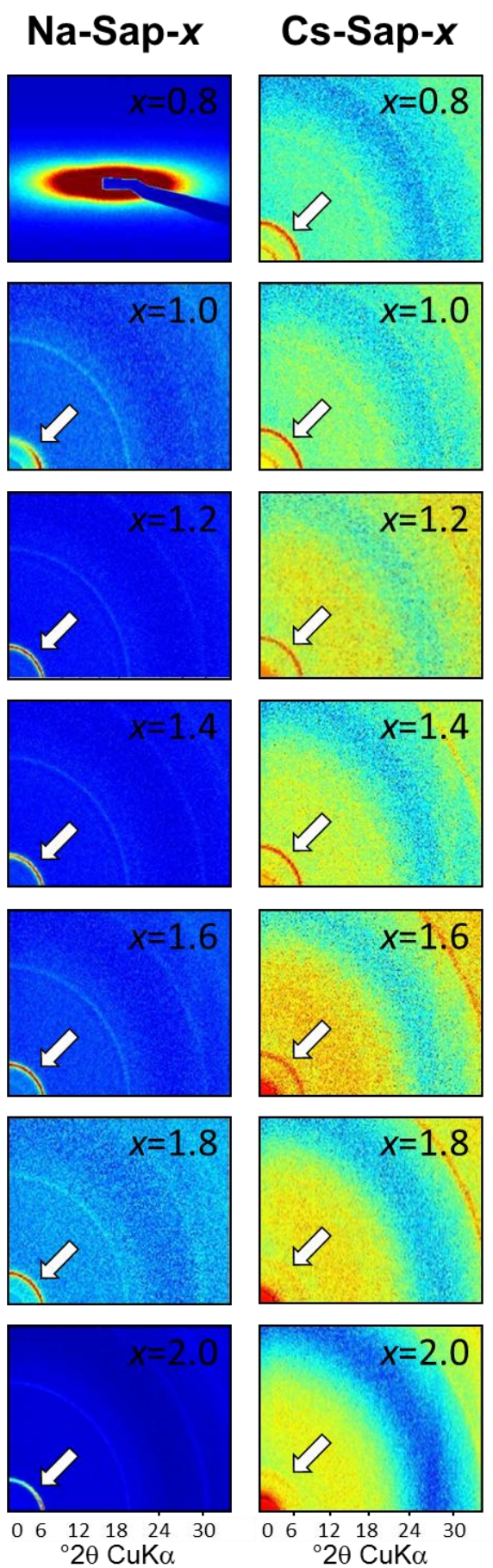

Figure 2. Experimental 2D WAXS patterns of Na-Sap- $x$ (left) and Cs-Sap- $x$ (right) sample series in water-saturated conditions. The layer charge $x$ is given per $\mathrm{O}_{20}(\mathrm{OH})_{4}$. The 001 reflection ring for each sample is marked by the white arrow. For Na-Sap-0.8 no diffraction feature was reported in the WAXS angular window and the 2D SAXS pattern collected for this sample is shown. For all samples the experimental $d_{001}$ values for all samples are reported in Table 1 . 


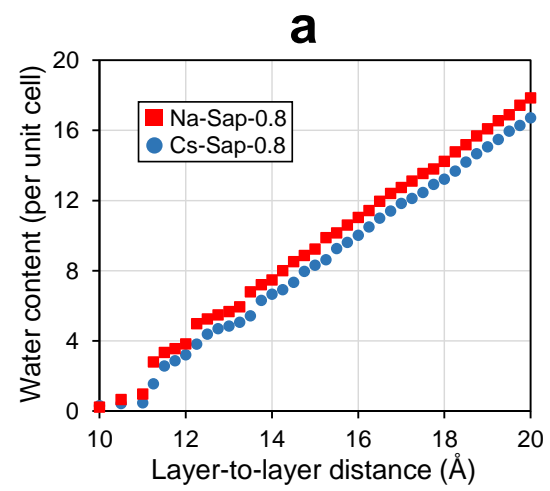

b

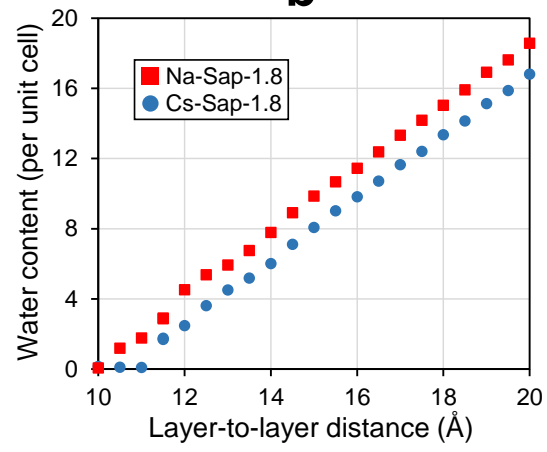

Figure 3. Water adsorption isotherms obtained from GCMC simulations for (a) low-charge and (b) high-charge samples with $\mathrm{Na}^{+}$or $\mathrm{Cs}^{+}$in the interlayer. 

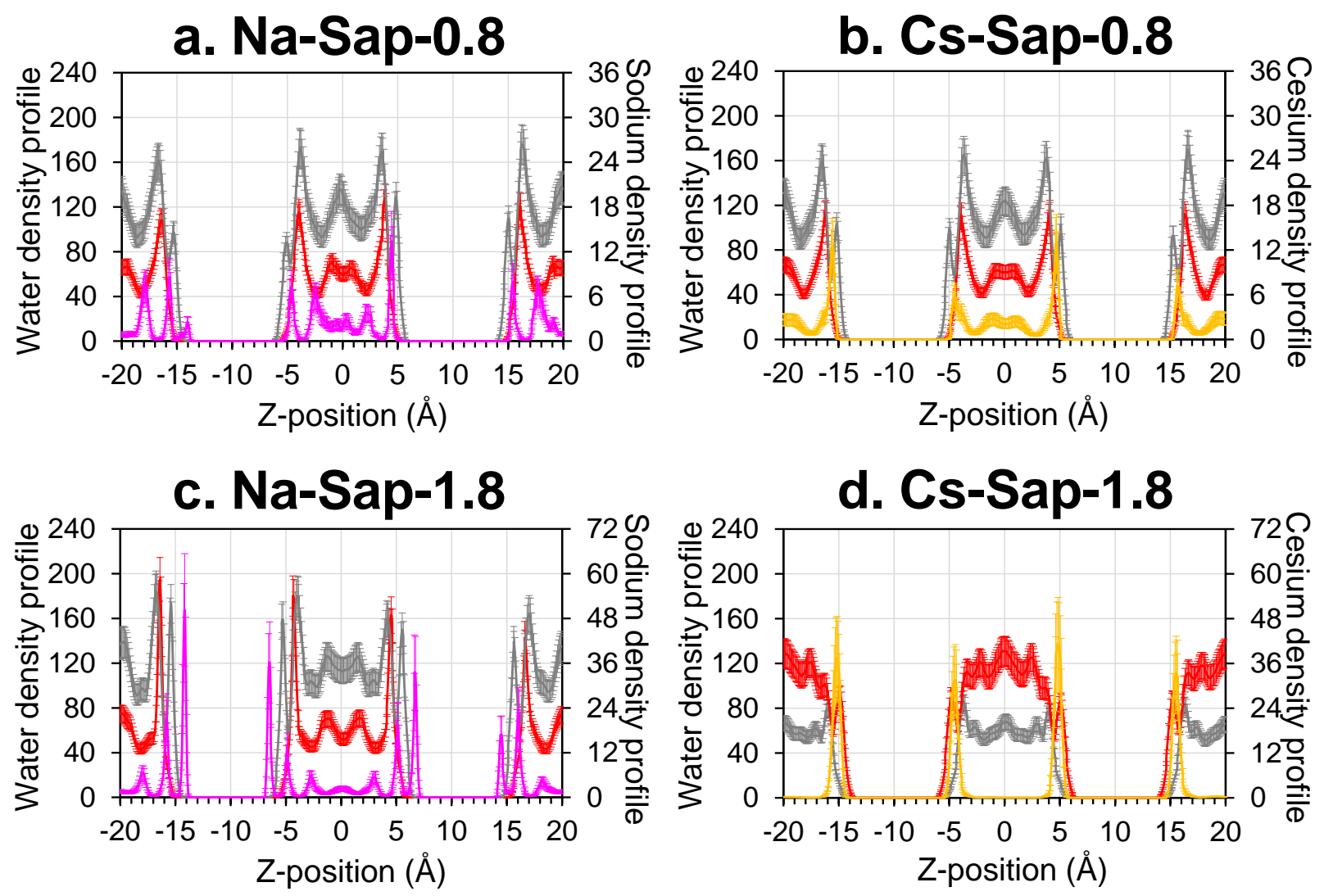

Figure 4. Atomic density profiles of oxygen, hydrogen, and interlayer (sodium or cesium) atoms generated from GCMC simulations for a layer-to-layer distance of $20 \AA$. Sample (a) Na-Sap-0.8, (b) Cs-Sap-1.8, (c) Na-Sap-0.8 and (d) Cs-Sap-1.8. Profiles for oxygen, hydrogen, sodium, and cesium atoms are shown in red, gray, pink, and orange respectively. Atomic z-coordinates (in $\AA$ ) are given relative to the midplane of the simulation box. 

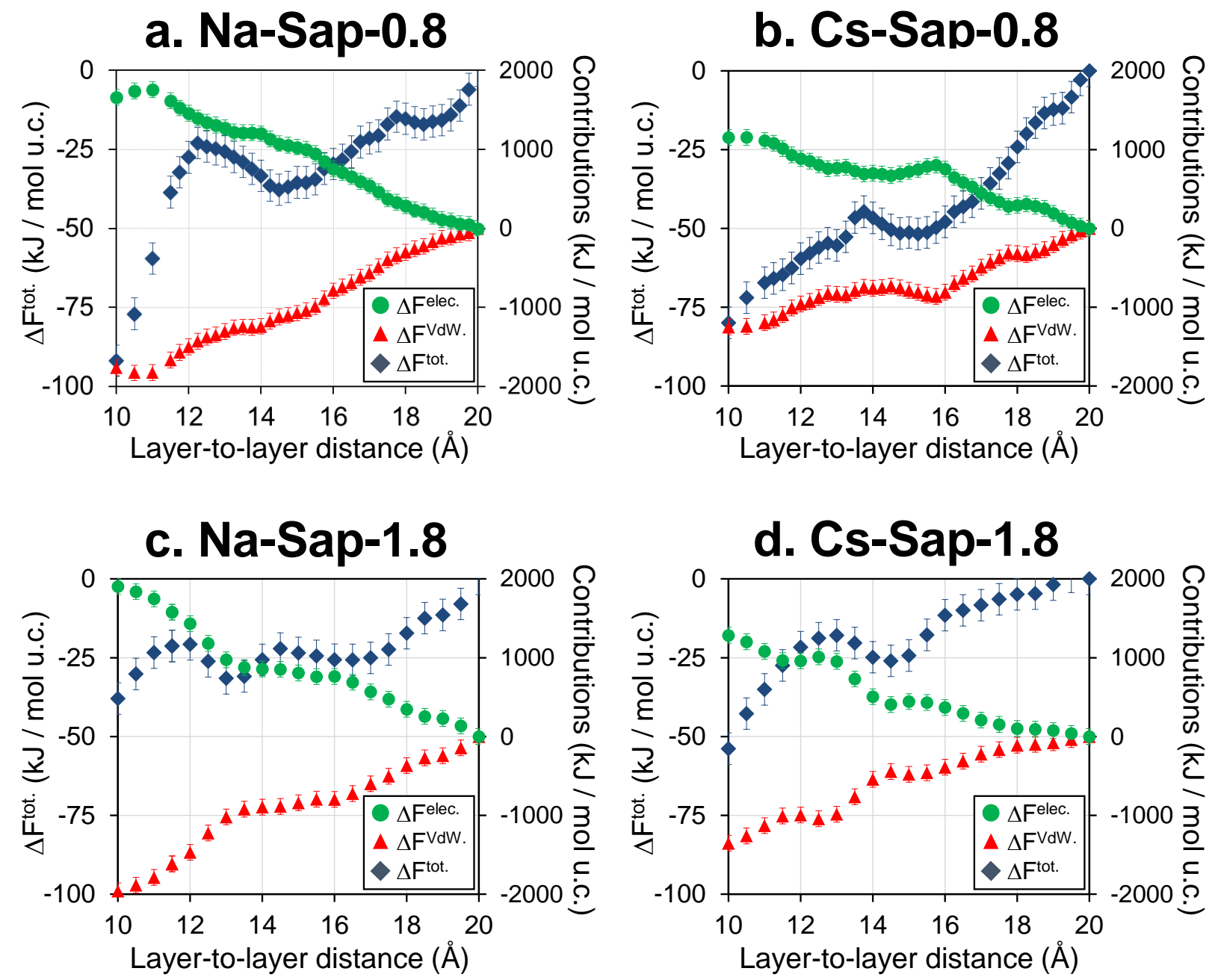

Figure 5. Evolution of the computed total interfacial free energy ( $\Delta \mathrm{F}^{\text {tot. }}$ in blue $)$ as well as its electrostatic $\left(\Delta \mathrm{F}^{\text {elec. }}\right.$ in green $)$ and $\operatorname{Van}$ der Waals $\left(\Delta \mathrm{F}^{\mathrm{VdW}}\right.$ in red) components (in $\mathrm{kJ} / \mathrm{mol}$ of unit cell) as a function of the layer-to-layer distance (in $\AA$ ). Sample (a) Na-Sap-0.8, (b) Cs-Sap-1.8, (c) Na-Sap-0.8 and (d) Cs-Sap-1.8. 


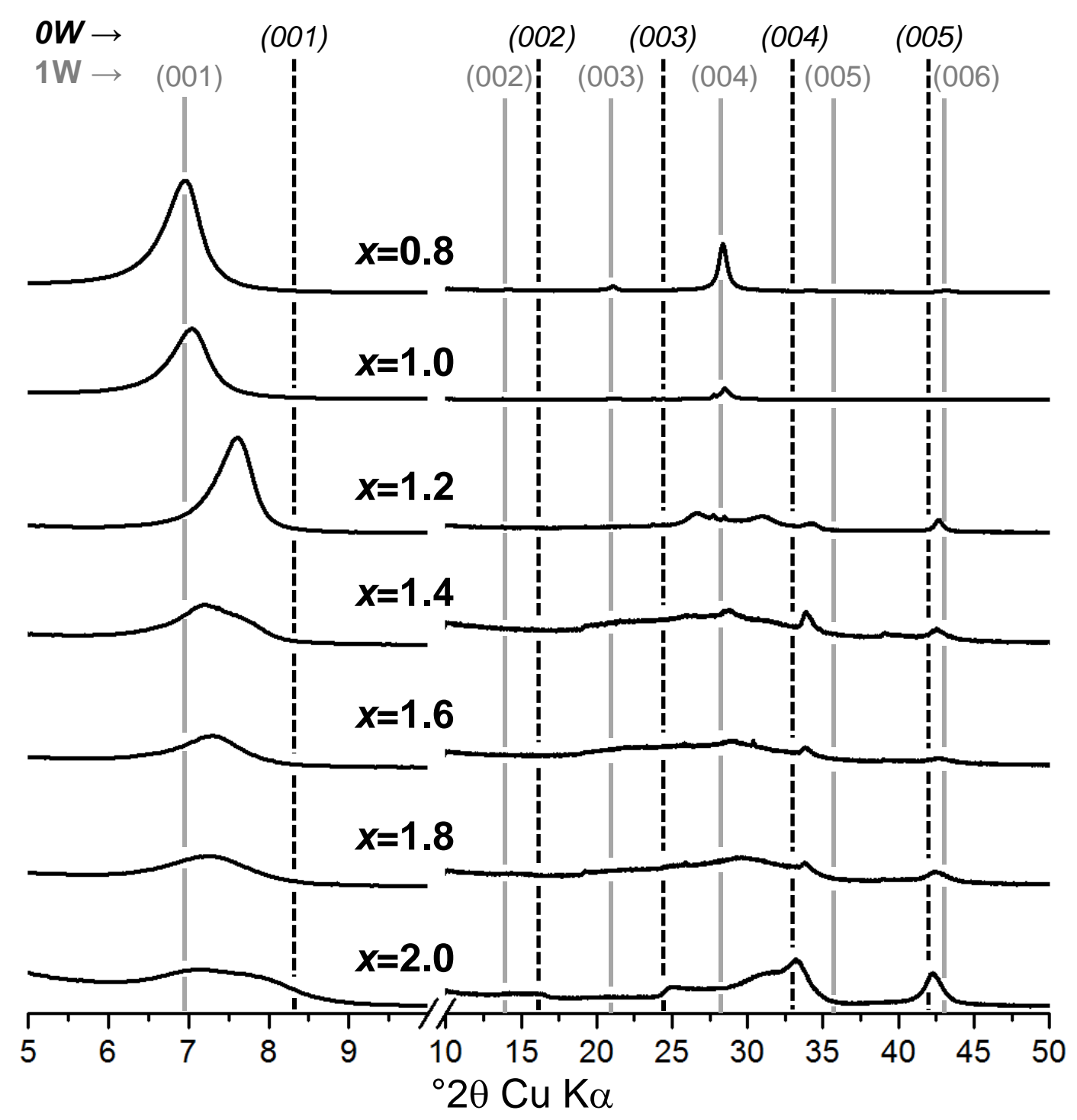

Figure 6. Experimental XRD patterns of Cs-Sap- $x$ oriented preparations at $80 \% \mathrm{RH}$ as a function of layer charge $x$ (per $\left.\mathrm{O}_{20}(\mathrm{OH})_{4}\right)$. The grey solid lines and dashed lines represent theoretical positions for $00 \ell$ reflections for periodic monohydrated $\left(1 \mathrm{~W} ; d_{001}=12.7 \AA\right)$ and dehydrated $\left(0 \mathrm{~W} ; d_{001}=10.8 \AA\right)$ structures, respectively. A x $3 \mathrm{y}$-scale factor is applied for relative intensities after $10^{\circ} 2 \theta$ for clarity. 


\section{a. Cs-Sap-0.8}
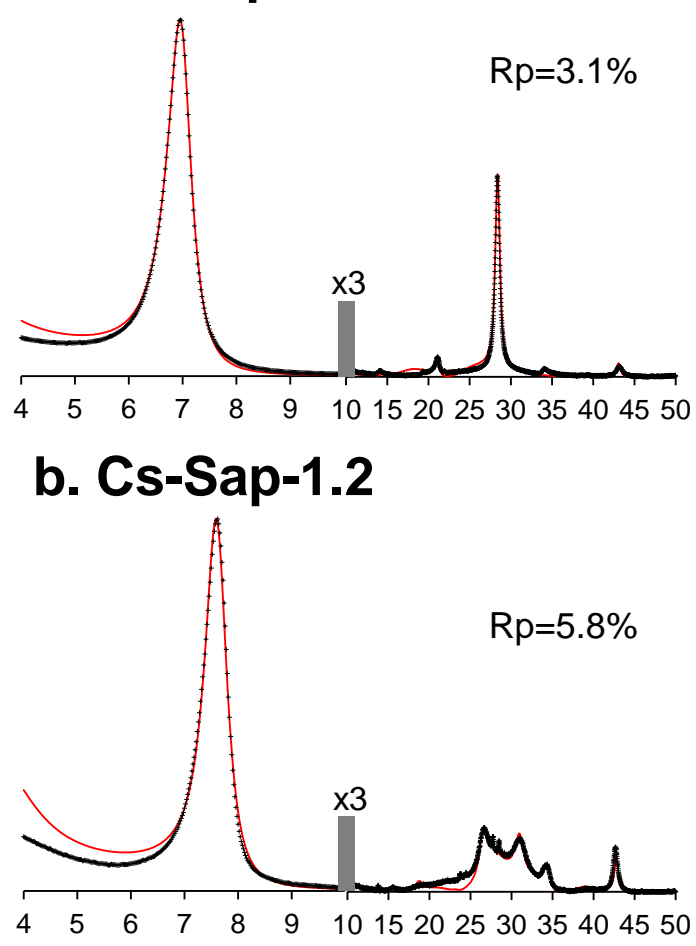

\section{c. Cs-Sap-2.0}

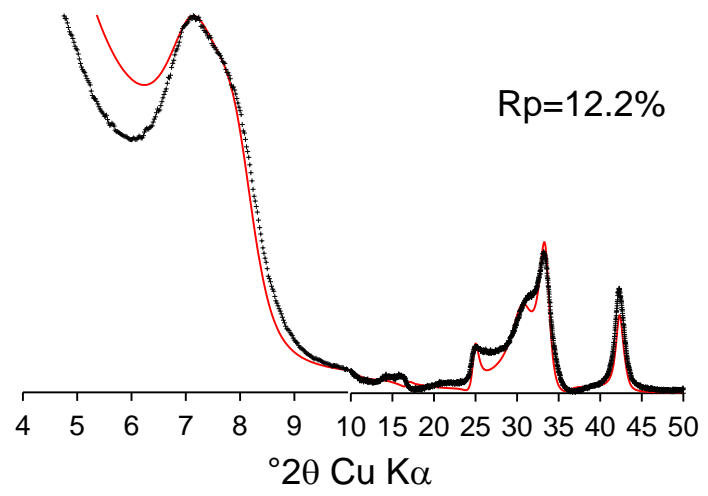

Figure 7. Comparison of experimental XRD patterns (crosses) and calculated profiles (red solid line) for oriented preparations of (a) Cs-Sap-0.8, (b) Cs-Sap-1.2, and (c) Cs-Sap-2.0 samples. The calculated profiles account for the interstratification of hydrated $(2 \mathrm{~W}$ or $1 \mathrm{~W})$ and collapsed layers in different relative proportions (Table 4). The vertical grey bars indicate modified intensity scale factor for the high-angle regions of the patterns as compared to the low-angle region. The Rp parameter indicates the goodness of the fit. 

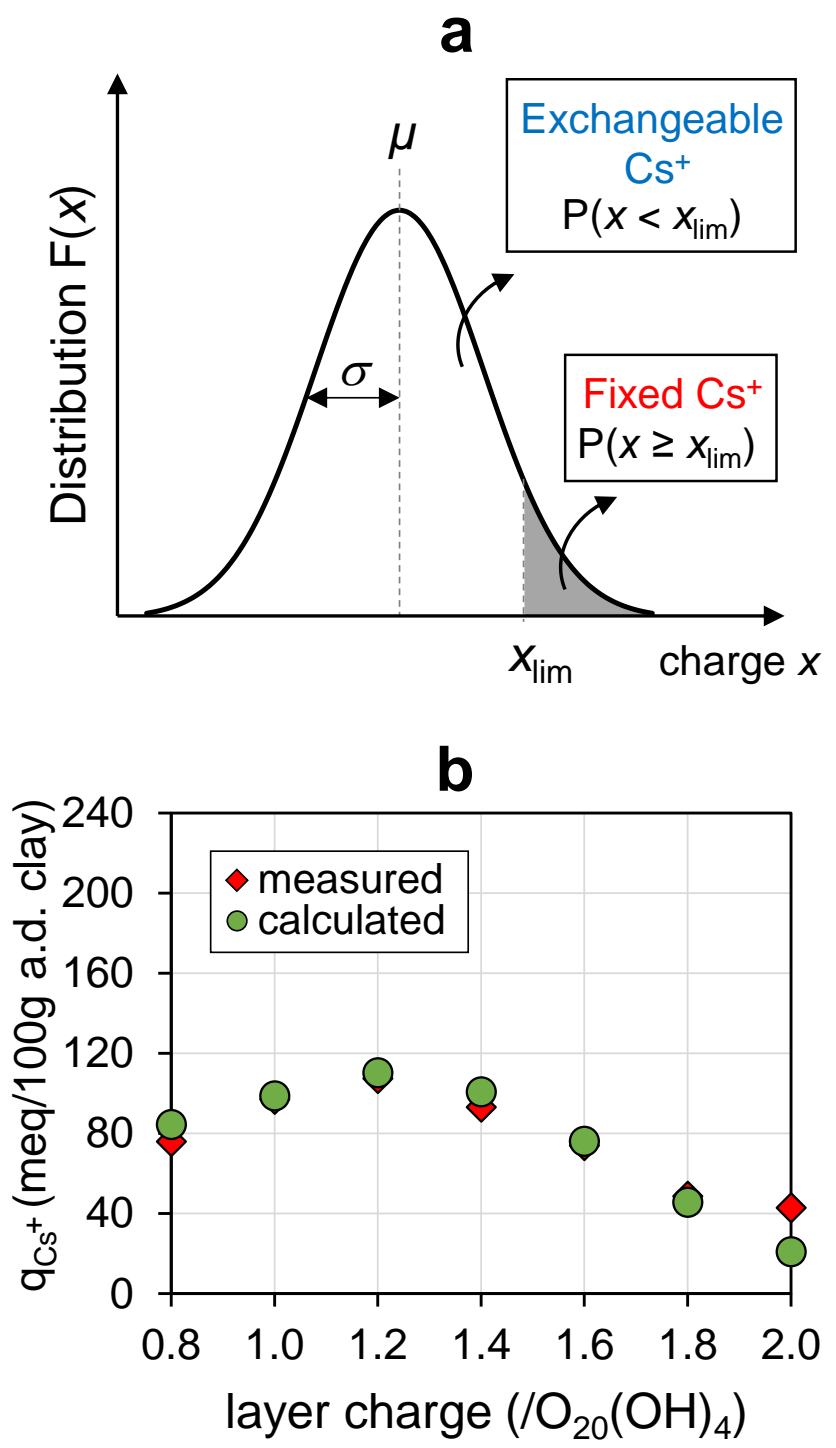

Figure 8. (a) Model with normal distribution of charge $x$ between layers for a given sample of mean layer charge $\mu$. Fraction of layers with exchangeable $\mathrm{Cs}^{+}$amounts is represented by the relative fraction $P\left(x<x_{\text {lim }}\right)$ of swelling layers having a charge below the limit charge value $x_{\text {lim }}$. (b) Comparison between experimental extractable $q_{C s^{+}}$amounts and those predicted by the model based on heterogeneous charge distribution with input parameters $\sigma=0.34 / \mathrm{O}_{20}(\mathrm{OH})_{4}$ and $x_{\text {lim }}=1.65 / \mathrm{O}_{20}(\mathrm{OH})_{4}$. 